NBER WORKING PAPER SERIES

\title{
RECRUITING AND SUPPORTING LOW-INCOME, HIGH-ACHIEVING STUDENTS AT FLAGSHIP UNIVERSITIES
}

\author{
Rodney J. Andrews \\ Scott A. Imberman \\ Michael F. Lovenheim \\ Working Paper 22260 \\ http://www.nber.org/papers/w22260
NATIONAL BUREAU OF ECONOMIC RESEARCH 1050 Massachusetts Avenue
Cambridge, MA 02138 May 2016

We gratefully acknowledge that this research was made possible through data provided by the University of Texas at Dallas Education Research Center. The conclusions of this research do not necessarily reflect the opinions or official position of the Texas Education Agency, the Texas Higher Education Coordinating Board, or the State of Texas. We would also like to thank Sara Muehlenbein, Alyssa Carlson and Mark Lu for excellent research assistance. We are further grateful for generous financial support for this project provided by the Greater Texas Foundation, the Russell Sage Foundation and the William T. Grant Foundation. Finally, we'd like to thank seminar participants at the Association for Education Finance and Policy Annual Meeting, Brookings Institution, CESifo Economics of Education Conference, Dalhousie University, Institute for Research on Poverty Summer Research Workshop, Michigan State University, Middle Tennessee State University, NBER Education Working Group Meeting, Society of Labor Economists Annual Meeting, the Swedish Institute for Social Research (SOFI), Syracuse/Cornell Summer Education Seminar, United States Military Academy, University of Michigan, University of Rochester, University of Virginia, and Vanderbilt University for helpful comments. The views expressed herein are those of the authors and do not necessarily reflect the views of the National Bureau of Economic Research.

NBER working papers are circulated for discussion and comment purposes. They have not been peer-reviewed or been subject to the review by the NBER Board of Directors that accompanies official NBER publications.

(C) 2016 by Rodney J. Andrews, Scott A. Imberman, and Michael F. Lovenheim. All rights reserved. Short sections of text, not to exceed two paragraphs, may be quoted without explicit permission provided that full credit, including $\odot$ notice, is given to the source. 
Recruiting and Supporting Low-Income, High-Achieving Students at Flagship Universities Rodney J. Andrews, Scott A. Imberman, and Michael F. Lovenheim

NBER Working Paper No. 22260

May 2016

JEL No. H75,I23,J24

\begin{abstract}
We study two interventions in Texas that were designed to overcome multiple hurdles faced by low-income, high-ability college students. The Longhorn Opportunity Scholars (LOS) and Century Scholars (CS) programs recruited at specified low-income high schools, provided additional financial aid, and enhanced support services once enrolled in college if students attended University of Texas - Austin or Texas A\&M - College Station, respectively. These flagship institutions are widely regarded as the top public universities in Texas. Using administrative data that links K-12, postsecondary, and earnings records for Texas public college students, we find via difference-in-differences estimates that the LOS program had a large, positive effect on high-achievers: attendance at UT-Austin increased by 2.2 percentage points $(81 \%)$, and the likelihood of graduating from UT-Austin increased by 1.7 percentage points $(87 \%)$. Twelve or more years post-high school, earnings of those exposed to LOS rose by $4.0 \%$. These results entirely come from women, who saw enrollment at UT-Austin increase by 4.0 percentage points, graduation from UT-Austin increase by 2.6 percentage points and earnings increase by $6.1 \%$. We find no evidence that the CS program affected any postsecondary or labor market outcomes. These results indicate that targeted recruitment combined with adequate supports and financial aid can substantially increase enrollment of low-income students in higher quality colleges and improve labor market outcomes. However, the differences in the LOS and CS program effects highlight the importance of understanding how to design these programs to maximize their impact on students.
\end{abstract}

Rodney J. Andrews

The University of Texas at Dallas

800 West Campbell Road

MS WT21

Richardson, TX 75080

and NBER

rodney.j.andrews@utdallas.edu

Scott A. Imberman

Michigan State University

486 W. Circle Drive

110 Marshall-Adams Hall

East Lansing, MI 48824-1038

and NBER

imberman@msu.edu
Michael F. Lovenheim

Department of Policy Analysis and Management

Cornell University

102 Martha Van Rensselaer Hall

Ithaca, NY 14853

and NBER

mfl55@ cornell.edu 


\section{Introduction}

Changes in the US economy over the past several decades have led to historically high demand for skilled labor (Autor, Katz and Kearney 2008), which has substantially increased the earnings premium associated with having a college degree (Autor 2014). These rising returns to college investment have been met with sluggish increases in postsecondary attainment, particularly among students from low-income backgrounds (Lovenheim and Reynolds 2013; Bailey and Dynarski 2011). The postsecondary education investment gap across the income distribution combined with the large earnings premium associated with collegiate training suggests that the current higher education system may contribute to, rather than mitigate, growing income inequality in the US. Indeed, some evidence suggests that changes in the earnings premium associated with college can explain between 60 and 70 percent of the rise in income inequality over the past several decades (Goldin and Katz 2007). Developing policies that can support successful college investment by students from low-income backgrounds is of primary policy importance.

Differences in postsecondary attainment between low-income and high-income students take two forms. The first is that students from low-income families are much less likely to attend college at all (Bailey and Dynarski, 2011; Carneiro and Heckman, 2002) 1. ${ }^{1}$ The second type of investment gap, which has received far less attention, is that low-income students tend to enroll in schools of lower quality than their higher-income counterparts (Hoxby and Avery 2013). In the NLSY97, only $2 \%$ of low-income students attended a flagship public school, while among the highest-income students $16 \%$ did.2 The likelihood of attending a private school also increases with income, and the proportion of students enrolling in a two-year school declines with income. There is substantial evidence of large impacts of college quality on completion (Cohodes and Goodman 2014; Bound, Lovenheim and Turner 2010), time to degree (Bound, Lovenheim and Turner 2012), and subsequent earnings in the labor market (Andrews, Li and Lovenheim 2016; Hoekstra 2009; Black and Smith 2006, 2004; Brewer, Eide and Ehrenberg

\footnotetext{
${ }^{1}$ Tabulations from the 1997 National Longitudinal Survey of Youth (NLSY97) show that while only $13 \%$ of students from families with earnings over $\$ 125,000$ do not attend college, $56 \%$ of students from families with income below $\$ 25,000$ do not attend college. As family income increases, the likelihood of attending college increases steeply.

${ }^{2}$ This is not just a reflection of the differences in enrollment. Among those who enroll in any college, $3.7 \%$ of low-income students enroll in a public flagship university, and $18.4 \%$ of high income students enroll in this school type.
} 
1999) $!^{3}$ Hence, differences in college quality between low-income and high-income students could significantly affect gaps in both collegiate attainment and earnings.

To develop policies to address the gaps in postsecondary investment that exist across the income distribution, it is critical to understand why they are present. There are five main explanations for why students from low-income households tend to graduate from college in general, and from more elite colleges in particular, at lower rates. First, families with fewer resources at the time of college usually have fewer resources with which to invest in a child throughout his or her life. These "long run credit constraints" create differences in academic preparation for college among high school students (Cameron and Taber 2004; Carneiro and Heckman, 2002). Second, there is increasing evidence that low-income students face information gaps that often preclude them from applying to and enrolling in more selective schools, even when they are academically qualified to do so and would pay little to nothing in out-of-pocket costs (Hoxby and Avery 2013; Hoxby and Turner 2013). A third explanation is that low-income students are affected by both academic and social "mismatch" when they enroll in higher-quality schools. On average, these students have worse academic preparation for college and often are not part of the dominant cultural majority, particularly at more elite postsecondary institutions (Aucejo, Arcidiacono and Hotz 2013; Arcidiacono and Koedel, 2014; Arcidiacono et al., 2011; Dillon and Smith 2013). Mismatch effects could lower academic attainment among low-income students who enroll in more-selective colleges. Fourth, the complexity of the financial aid application may prevent students from applying for aid, and thus attending more expensive schools (Dynarski and Scott-Clayton, 2013, 2008, 2006; Bettinger, et al., 2012). Finally, resource constraints at the time of the college enrollment decision may prevent families from investing in a higher-quality school (Lovenheim and Reynolds 2013).

Prior research has found at most modest effects on student outcomes of policies designed to overcome any one of these disadvantages. One explanation for these results is that there are interactive effects of student disadvantage, making it necessary for programs to address several of these barriers simultaneously to effectively support postsecondary education among students from low-income backgrounds. In this paper, we present what is to our knowledge the first

\footnotetext{
${ }^{3}$ Dale and Krueger $(2013,2002)$ find little overall impact of college quality on earnings, but they do find sizable returns to college quality for low-income students.
} 
analysis in the literature of interventions aimed at addressing this broad array of disadvantages faced by low-income students. The Longhorn Opportunity Scholarship (LOS) program at the University of Texas at Austin (UT, ) and the Century Scholars (CS) program at Texas A\&M University - College Station, which are the two flagship schools of the Texas public higher education system, began in 1999 and 2000, respectively $4^{4}$ The programs targeted Texas public high schools that served low-income students in urban areas and traditionally sent few students to these institutions. Together, the LOS and CS programs were implemented in 110 high schools in Texas.

While entirely independent, both programs offered a suite of interventions that attempt to overcome the multiple disadvantages faced by low-income students in the higher education system: lack of information about college quality, less academic preparation for college, and lower financial resources. The programs engage in extensive outreach and recruiting, with university staff providing information sessions and, for the CS program, students going back to their high schools to share their experiences. This outreach and recruitment of students from low-income high schools helps overcome information barriers that may preclude students from these schools from applying to and enrolling in an elite postsecondary school. Program participants also are provided scholarships to help alleviate financial strain. Since most of these students qualified for substantial Federal grants, students in these programs would often have sufficient grant aid to fully cover tuition and fees $5^{5}$ Once enrolled, the LOS and CS programs include multiple but distinct academic support services for students as well as policies that help foster cohesion among the students. These services can help overcome social and academic mismatch. Critically, the programs did not provide students with help in the admissions process; all students who were induced to attend UT-Austin and Texas A\&M were academically qualified to attend those schools in the absence of these interventions.

We use administrative data from the State of Texas that links K-12 education records with higher education enrollment and performance information as well as earnings records from the

\footnotetext{
${ }^{4}$ Details on the Century Scholars program can be found at https://scholarships.tamu.edu/Scholarship-Programs/ Century-Scholars The Longhorn Scholars Program has since been discontinued though a description can be found in internet archives at https://web.archive.org/web/20030622194253/http://www.utexas.edu/student/finaid/scholarships/los_ index.html.

${ }^{5}$ For example, CS scholars currently receive $\$ 5,000$ per year for four years. Assuming scholarship amounts did not change, this covered most of the $\$ 5,639$ cost for tuition and fees in 2004. Similarly, LOS scholars in 2002 received $\$ 4,000$ per year from the program. Tuition at UT-Austin in 2005 was $\$ 7,286$.
} 
Texas unemployment insurance system. We exploit the roll-out of the LOS and CS programs to identify their effects on higher education outcomes and post-college earnings in a differencein-difference framework. Because these interventions were targeted towards high-performing students, we first generate a performance index using students' high school test score information. Our analysis focuses on high-achieving students, who we define as the top $30 \%$ of students within each high school on this performance index. The LOS and CS treatments targeted schools serving disadvantaged populations; many untreated high schools (such as those in wealthy suburban areas) differ substantially from treated schools in both their observed characteristics and outcomes, which makes them poor candidates for inclusion in the control group to estimate counterfactual trends. We therefore construct "trimmed common support" samples for each intervention using the rich information we have about the demographics and collegesending patterns of each high school in Texas prior to 1999 combined with information on the criteria UT-Austin and Texas A\&M say they used to select the schools. Hence, our resulting analysis samples are comprised of the set of schools that are more observationally-similar across the treatment and control groups than would be the case if we used all public high schools in Texas.

Conditional on the observed characteristics of schools, much of the targeting for these programs was based on geography. This makes it likely that there are equivalent control schools that did not receive the treatment because of where they were located rather than because of the populations of students they serve. We estimate difference-in-difference models using these trimmed common support samples in which we compare changes in outcomes among high-ability students in treated schools to changes in outcomes for high-ability students in observationally-similar untreated schools when the LOS/CS programs are implemented. The main identification assumption in these models is that the trends in enrollment patterns and outcomes among high-achieving students would have been the same in treated and control high schools absent the programs. We show extensive evidence of common trends in enrollment behavior, postsecondary outcomes, and labor market outcomes prior to the implementation of the treatments and find little evidence of demographic shifts among students due to the treatments. These findings strongly support our empirical strategy. 
The results of our analysis differ across programs. The LOS program had a large effect on the likelihood students enrolled in UT-Austin, increasing the enrollment rate by 2.2 percentage points ( $81 \%$ of the pre-treatment mean). These students were drawn predominantly from "emerging research universities" (ERUs), which are the set of public four-year schools that are the next quality tier down from the flagships. Six-year graduation rates from UT-Austin increased substantially among students at LOS high schools: they were 1.7 percentage points (87\% of the pre-treatment mean) more likely to graduate from UT-Austin. While there is no significant increase in overall graduation rates, we nonetheless find that earnings of high achieving students who attended LOS high schools increased by $4 \%$ twelve or more years after HS graduation. Given that the treatments are a package that includes an increase in college quality for some, extra financial aid for most, and support services while enrolled for all who participate, one can reasonably approximate a treatment on the treated effect by scaling the earnings effect by the share of students in the treated sample who attend UT after the program begins. This back-of-the-envelope treatment effect is equivalent to a $70 \%$ increase in earnings. While large, we argue this effect size is reasonable when one considers that the targeted population is high achieving, low income, and heavily minority. Such groups may be especially sensitive to an intervention like this. We further note that all of the effects we see are concentrated among women. There is no impact on either male enrollment or earnings but a 4.0 percentage point increase in female UT enrollment and a $6.1 \%$ increase in female earnings.

In contrast to the LOS results, the CS program does not lead to a change in where students attend college. In particular, it does not increase the likelihood students attend Texas A\&M College Station, nor does it reduce UT-Austin enrollment. Consistent with the lack of enrollment effects, our results do not point to any impact of the CS program on postsecondary or labor market outcomes. It is somewhat surprising that the CS and LOS programs have such different effects. We argue this difference is likely driven by the fact that the LOS program was larger in scope and the academic support services were more intensive. All students attending UT-Austin from an LOS school received the academic support services, in contrast to the CS program that limited services to scholarship recipients. The LOS support services were much more academically-focused than in CS as well, and conversations with an LOS program official 
suggests that the recruitment efforts associated with the LOS program were more intensive. While the LOS program generates large long-run benefits for exposed students, the CS results suggest that the design and implementation of these programs matter. Our findings underscore the promise of the type of comprehensive support strategies we study but also highlight the need to understand how best to design them in order to maximize their positive effects.

\section{The Longhorn Opportunity and Century Scholars Programs}

\subsection{Program Description}

The Longhorn Opportunity Scholars and Century Scholars Programs were first implemented in 1999 and 2000, respectively, to increase enrollment rates for low-income and minority students at UT-Austin and Texas A\&M in the wake of the state's 1997 affirmative action ban. This ban made it illegal for schools in the state to consider race as a factor in either admissions or the provision of financial aid. The pre-existing affirmative action system was replaced by the Texas Top 10\% Rule in 1998, which stipulated that any student in the top $10 \%$ of his or her high school class could attend any Texas public university.6 Post-1997, the vast majority of students in UT-Austin and Texas A\&M were admitted under this rule. As a result of the Top 10\% rule, during the period we study, students ranked outside the top 10 percent of their class at high schools serving low-income students were very unlikely to enroll in UT-Austin or Texas A\&M.

Despite the fact that many students from low-income schools became eligible to attend Texas A\&M and UT-Austin under this rule, minority enrollment at these colleges fell dramatically (Kain, O'Brien and Jargowsky 2005). In response to these declines, the LOS and CS programs were developed to try to recruit students from low-SES backgrounds to the state flagships and to support their academic success while enrolled. The LOS program targeted 70 high schools in Houston, Dallas, San Antonio, El Paso, Beaumont and Laredo that had high shares of low-income and minority students and few prior applicants to UT-Austin. The CS program similarly targeted 70 low-income schools in Houston, Dallas and San Antonio with few prior applicants to Texas A\&M 7 There was some overlap between the two programs, with students

\footnotetext{
${ }^{6}$ The ranking is determined by each high school separately, but typically is based on student grade point average.

${ }^{7}$ Since 2003, the CS program has expanded further and the LOS program has been replaced by the Discovery Scholars Program. This program has many of the same elements as LOS, but eligibility is individual-based rather than high-school-based and support services are separated from scholarships. We do not study post-2002 cohorts in this analysis because they are too young to obtain
} 
from several high schools being eligible for both programs. Over 600 students are admitted to Texas A\&M and UT-Austin under these programs each year. Figures 1 and 2 show the geographic distribution of LOS and CS schools in our estimation sample, respectively. They are mostly located in the large urban centers in the state; the focus of these programs is on the urban poor. That these interventions are isolated to specific cities in Texas allows us to find similar schools throughout the state that are untreated to form our control group.

Though administered by different universities, the two programs are similar in a number of ways. First, most students are given additional financial aid if they enroll in the flagship school running the specific program. Second, there is an active recruiting effort made at targeted high schools to try and overcome any information barriers about cost, the likelihood of admission, and the value of attending a higher-quality school that may have existed. Third, once enrolled, the LOS and CS students are given access to academic support services. Fourth, both programs establish formal enrolled student and alumni communities that offer support, guidance, networking and resources.

Despite these similarities, there are two substantive differences across the programs that could lead them to have different effects on student outcomes. The first is their scope. For LOS, initially the plan was to only offer services to students who received financial support from the program, restricted to a maximum number of scholarships per high school. However, in practice they allowed all enrolled students from targeted schools to receive program services (but not the scholarship money). Furthermore, an administrator of the LOS program informed us that students who did not qualify for LOS scholarship money directly usually qualified for other scholarships. For CS, students from targeted high schools only received the academic support services if they are awarded the scholarship money. Students also had to maintain a minimum GPA in order to keep their CS fellowship.

The second difference between the programs is in the type of academic support services offered. Under the LOS program, students were offered extensive support, including guaranteed spaces in residence halls, free tutoring, and peer mentoring. In addition, the LOS program had students enroll in small sections of introductory courses in mathematics, chemistry, biology, economics and other fields exclusively for LOS students. These courses were widespread across reliable earnings estimates in our data. 
the university in multiple subject areas providing numerous opportunities for LOS students to take advantage of the courses. A list of courses with exclusive LOS sections is provided in Online Appendix Table A1. Instructors for these sections taught the same content but could tailor the instruction to recognize that the students were coming from disadvantaged backgrounds and likely had a lower baseline set of skills than the average first-year student. This may have been particularly useful in difficult courses in math and science where these types of course sections were popular. The academic support services in the CS program were much less extensive and entailed faculty mentoring (in lieu of peer mentoring) as well as professional training in public speaking, interviewing and presentation skills, while also maintaining a community service requirement.

These interventions could influence several important postsecondary outcomes and earnings in ambiguous directions that point to the need for an empirical analysis. In particular, we might expect the LOS/CS programs to have a positive effect on student outcomes because of the overall positive effects of college quality on educational attainment and earnings (e.g., Andrews, Li and Lovenheim, 2016; Bound, Lovenheim and Turner 2010; Hoekstra 2009; Black and Smith 2004, 2006; Brewer, Eide and Ehrenberg 1999) 8 Ex-ante, the LOS/CS programs should increase the likelihood that students enroll in UT-Austin and Texas A\&M. Indeed, in interviews with ten freshmen recipients of the Longhorn Opportunity Scholarship, Bhagat (2004) finds that the financial, social, and academic supports offered by LOS were the primary reasons that students selected the University of Texas at Austin, suggesting that the programs had positive effects on enrolling. This is consistent with the evidence in Domina (2007) of higher flagship enrollment after the LOS/CS program implementation and Andrews, Ranchhod and Sathy (2010) of higher SAT score sending to the flagships - a proxy for intent to apply to a given school - among students in treated high schools. Outside of the flagships, the other options for these students typically are worse in terms of the quality and resource levels of the institution, including attending lower-quality four-year schools, attending a two-year college or not attending college at all. We examine the enrollment effects of these programs directly below using richer and more comprehensive data on enrollment than were used in this prior work.

\footnotetext{
${ }^{8}$ Another potential mechanism is that increased financial support provided by the programs may help students progress through the higher education system by relaxing credit constraints. However there is very little evidence that credit constraints or financial aid have more than a modest impact on students' paths through college (e.g., Johnson 2013; Stinebrickner and Stinebrickner 2008; Bettinger 2004).
} 
Our results suggest a more nuanced story that differs across LOS and CS treatments.

To the extent that the LOS and CS programs increased flagship enrollment, they would lead to a substantial increase in college quality for treated students. To provide some context, USNews and World Report ranks UT-Austin as the $58^{\text {th }}$ and TAMU as the $68^{\text {th }}$ best national universities. The next highest public institutions in the state are UT-Dallas, ranked 145, Texas Tech, ranked 156, and University of Houston at 186. Table 1 provides information on selectivity and resources of Texas public institutions. The table compares University of Texas at Austin and Texas A\&M to "emerging research universities" (ERUs) and other four-year schools.9 The means in the table show that both flagships are substantially more selective than the ERUs and other 4-year institutions as measured by SAT scores of incoming students. The flagships also spend substantially more per-student, have lower student-faculty ratios, higher graduation rates and higher retention rates.

The ambiguity in predicted impacts of the programs from college quality improvements arises because of potential tension between overall college quality effects and the potential for academic "mismatch" that can occur when students of lower academic preparation are brought into a more demanding educational environment.10 The students affected by the LOS and CS programs tend to be high-achievers in their high schools, but because they come from lowincome schools, they still may be under-prepared for the academic rigor of a flagship university. Indeed, this is the reason that the programs offer academic support services. If attending a flagship causes these students to struggle academically, potentially leading to lower graduation, persistence and earnings, then the LOS/CS programs could be harmful. This could be especially problematic if the programs were simply recruiting students to attend or providing financial aid. However, the LOS and CS programs provide a system of social and academic supports that potentially mitigate, or even completely overcome, the effects of mismatch.

As a result of these conflicting theoretical impacts, a priori, it is not possible to determine the net effect of the targeted recruitment programs. The success or failure of these programs hence must be determined empirically. In addition to potentially reducing educational inequities,

\footnotetext{
${ }^{9}$ The ERU designation is for institutions that are eligible for a special pool of state funds for increasing research output. These are sometimes called "Tier 1" schools as part of the goal of the program is to increase the schools' research and academic reputations to the top tier of public universities in the US. For our purposes, this is a useful distinction as it provides a "second tier" of public institutions below the flagships but with better resources than other institutions. This group includes UT Arlington, UT El Paso, UT Dallas, UT San Antonio, Texas Tech University, University of North Texas, and the University of Houston.

${ }^{10}$ See Arcidiacono and Lovenheim (2015) for an overview of the "quality-fit" tradeoff in higher education.
} 
these programs may also help reduce income inequality if there are positive labor market impacts. Hence, it is critical to examine their effects on long-term outcomes such as educational attainment and earnings. These arguments underscore the importance of conducting a rigorous analysis that can identify the effects of these targeted recruitment programs on students.

\subsection{Prior Literature}

No prior work exists that examines the impact of a multifaceted treatment aimed at addressing the multiple disadvantages faced by students from low-income backgrounds at selective higher education institutions. However, there are several important studies that have examined programs containing individual components of the CS and LOS treatments. In particular, prior work has examined the impacts of college outreach programs and financial aid, with very little research being done on targeted college services. An important contribution of our analysis stems from the fact that it may not be enough to merely address one of the disadvantages faced by low-income students. Instead, to increase the postsecondary attainment of such students, particularly at highly-selective schools, it may be necessary to provide interventions that simultaneously affect a range of student disadvantages. Our study is the first to provide evidence on this type of broad intervention.

Previous research on college outreach programs has not found strong evidence they improve student academic outcomes. Using National Education Longitudinal Study of 1988 (NELS:88) data, Domina (2009) studies the effect of being exposed to a college outreach program that provides information on the college application process and, in some cases, tutoring support and college counseling services for high school students. Domina reports that about $5 \%$ of students in the NELS:88 sample are exposed to such a program. Using propensity score matching techniques, he finds little evidence that exposure to an outreach program influences high school achievement or college enrollment. In a randomized controlled trial of Upward Bound, Myers et al. (2004) find largely the same results, except for a positive four-year college enrollment effect.

These studies do not examine the impact on college quality other than the four-year/2-year margin. However, a major effect of the type of college outreach embedded in the CS/LOS 
programs might be to influence students to attend a flagship rather than a non-flagship school. There is some evidence that college outreach can positively influence the quality of schools to which students apply and enroll. Hoxby and Turner (2013) conduct a randomized controlled trial in which they send personalized information to high-achieving, low-income students on college enrollment strategies, expected financial aid, and their likelihood of admission. They find large increases in the quality of colleges to which students apply. The LOS and CS programs provide similar information as well as direct, in-person recruiting, and could have large effects on the college choices made by students in the targeted high schools ${ }^{11}$ For academic service provision, Angrist, Lang and Oreopoulos (2009) and Clotfelter, Hemelt, and Ladd (2016) provide the analyses most relevant to our study. In the former, the authors randomly assign students to receive peer mentoring and other services and/or financial incentives. They find that the services and incentives combined led to academic gains for women. The latter study looks at a program at University of North Carolina - Chapel Hill that provides financial assistance and academic support services to low income students. While they are not able to assess the impact of the program on sorting across schools (and hence see how it affects college quality) or labor market outcomes, they find significant increases in grades and graduation rates. Further, neither program had a recruitment component, which is a key feature of both the LOS and CS treatments.

Our research also relates to a body of work that examines the effect of financial aid on student collegiate choices and outcomes. Evidence from state merit aid programs that offer free or highly-reduced tuition to in-state students who attend a public institution suggest these programs are successful at altering the college enrollment decisions of high-achieving students (Cohodes and Goodman 2014; Cornwell, Mustard and Sridhar 2006; Dynarski 2000). However, these programs do not tend to increase students' academic performance in college and may reduce performance because they induce many students to enroll in lower-resource schools than they otherwise would have (Cohodes and Goodman 2014; Fitzpatrick and Jones 2012; Sjoquist and Winters 2012). Recent evidence from a randomized private scholarship in Nebraska, however, suggests aid receipt increases four-year enrollment, persistence and completion (Angrist

\footnotetext{
${ }^{11}$ Other work has focused on reducing psychic and financial barriers to the application process. For example, Bettinger et. al. (2012) find that providing assistance with the FAFSA increases college applications and enrollment amongst low income students while Pallais (2015) finds that increasing access to free ACT score reports increases the amount of schools low income students apply to and the quality of the schools they attend.
} 
et al. 2014).

Importantly, the LOS and CS programs should have the opposite college quality effect to what has been found in the merit aid literature. The likely alternative for these students is a less-selective and lower-resource state university, community college or no college at all 12 UT-Austin and Texas A\&M-College Station have much higher per-student expenditures, lower student-faculty ratios and significantly higher 6-year graduation rates (Table 1). In addition, both flagships have student bodies with higher measured pre-collegiate academic ability relative to other public colleges and universities in Texas, as measured by the SAT score. Any resulting peer effects, therefore, may play a role in driving the education differences across these schools and could have a positive impact on LOS/CS students (Stinebrickner and Stinebrickner 2006; Zimmerman 2003; Sacerdote 2001).

Finally, much prior research has examined the Texas Top $10 \%$ rule, which provides an important institutional backdrop for our analysis. The Top 10\% rule was implemented in 1998 as an alternative to affirmative action. It gave automatic admission to any student in the top $10 \%$ of his or her high school class to any public college or university in Texas. There is a large literature exploring the effect of the Texas Top $10 \%$ rule on enrollment and completion outcomes, especially among minority students. This research tends to find that the plan increases enrollment among high-achieving students at flagship schools (Daugherty, Martorell and McFarlin 2014; Niu and Tienda 2010; Domina 2007; ), especially those who were in high schools that traditionally did not send many students to these schools (Long and Tienda 2008; Domina 2007). The effects on completion are more ambiguous, with some studies finding a negative effect (Cortes 2010) and some finding no effect (Daugherty, Martorell and McFarlin 2014). We discuss in Section 4 how this policy affects our identification strategy.

\section{Data}

The data we use in this study come from three sources: administrative data from the Texas Education Agency (TEA), administrative data from the Texas Higher Education Coordinating

\footnotetext{
${ }^{12}$ While it is possible that some students would have attended private or out-of-state schools, such behavior is likely rare for the population targeted by LOS/CS. We cannot directly test for such sorting with our data as we only observe attendance at public institutions in Texas. However, we find no evidence that the likelihood of attending any postsecondary public institution changed as a result of the programs.
} 
Board (THECB), and quarterly earnings data from the Texas Workforce Commission (TWC). The data are housed at the Texas Schools Project, at the University of Texas at Dallas Education Research Center (ERC). These data allow one to follow a Texas student from Pre-Kindergarten through college and into the workforce, provided individuals remain in Texas. We discuss each of these data sets in turn.

Beginning in 1992, the TEA began collecting administrative data on all students enrolled in public schools in Texas. These data contain students' grade level, the school in which he or she is enrolled, scores from state standardized tests, and a host of demographic and educational characteristics such as race/ethnicity, gender, special education status, whether the student is eligible for free or reduced-price lunch, whether the student is at risk of dropping out, and enrollment in gifted and talented programs. The test score data we use are from the $11^{\text {th }}$ grade Texas Assessment of Academic Skills (TAAS) exams for reading, writing and mathematics. The TAAS exams were administered to all students in Texas through 2002, and they were "high stakes" in the sense that students had to achieve a passing score on them in order to graduate. Because students can retake them, we use the lowest score for each student, which typically corresponds to the score from the first time students take the exam. Although the TEA data begin in 1992, in 1994 Texas redesigned the high school exams. We therefore restrict to students who graduate in the high school classes of 1996-2002.

The LOS/CS programs targeted only high-ability students at each school. Hence, we focus our analysis on the top of the within-school achievement distribution. We estimate the students' academic ability as the first principal component of a factor analysis model that includes $11^{\text {th }}$ grade TAAS scores on mathematics, reading and writing. As argued by Cunha and Heckman (2008) and Cunha, Heckman and Schennach (2010), combining test scores in a factor model provides a stronger proxy for student academic ability than using any one test score alone. Using this academic ability factor, we rank students in his or her school-specific $11^{\text {th }}$ grade cohort. Andrews, Li and Lovenheim (2016) present evidence that the within-high school rank on these exams is highly correlated with whether one is admitted to a flagship university through the Top $10 \%$ Rule ${ }^{13}$ which is evidence that the relative rank on these exams is a good proxy for

\footnotetext{
${ }^{13}$ Specifically, Andrews, Li and Lovenheim (2016) show that admission through the Top 10\% Rule is highly predictive of attending UT-Austin or Texas A\&M, but conditional on the relative rank on the TAAS test scores this variable loses its predictive power.
} 
relative academic rank in each high school.

Our higher education data from the THECB contain detailed information about college enrollment and key collegiate outcomes for all students who enroll in a public college or university in the State of Texas. For these students, we observe the enrollment decision in every public college or university in each semester, major choice, and the timing of all degrees received ${ }^{14}$ The quarterly earnings data from the TWC are from Q1 2007 through Q1 2015 and contain earnings for every worker in Texas, with the exception of those working for the Federal Government or US Postal Service. Because the LOS and CS programs are relatively recent, we are constrained in the length of the post-high school time period over which we can observe earnings. We construct three measures of earnings to provide insight into the role of timing. The first is average log quarterly earnings in all quarters in which earnings are observed six or more years post-high school graduation. The second uses all earnings observations that are at least ten years after high school graduation and the third uses twelve or more years after high school.

To construct our earnings measure, we first restrict the sample to individuals with at least five quarters of $\$ 100$ or more earnings in the relevant time period $(6+, 10+$ or $12+$ years after high school graduation) and drop the highest $0.5 \%$ of overall earnings quarters due to the long right tail of the earnings distribution.15 We then demean log quarterly earnings within year-quarter-cohort bins so that earnings are relative to the mean earnings within a high school graduating cohort at a given time. ${ }^{16}$ We then average the demeaned earnings within individuals to generate an adjusted log earnings measure.

A limitation of our data is that students only are followed if they both attend college in Texas and work in Texas in an industry covered by unemployment insurance. Biases due to differential attrition associated with the rollout of LOS and CS therefore can occur both in the

\footnotetext{
${ }^{14}$ Ideally we would be able to look at GPA as well but unfortunately collection of GPA data by the state was not universal across institutions until 1999 .

${ }^{15}$ We provide details on results using alternative sample constructions in Online Appendix Table A-11. Dropping the top 0.5\% of earnings quarters has little affect on the earnings estimates but reduces the standard errors. The $99.5^{\text {th }}$ percentile of the quarterly earnings distribution is $\$ 94,928$.

${ }^{16}$ We also exclude all earnings that occur while an individual is enrolled in a Texas public graduate school as these earnings are unlikely to be reflective of permanent earnings (we do not observe if the student is enrolled in a private or out-of-state graduate school). Further, we note that a worker-quarter is only observed if the worker has positive earnings in that quarter. Missing observations can be due to unemployment, labor force non-participation or leaving the State of Texas. We do not include missing observations as zeros because we are unsure whether an individual has left the state or is not working and residing in Texas. These sample restrictions and the way in which we construct our earnings measures are very similar to the methods used by Andrews, Li and Lovenheim $(2014 ; 2016)$ with these data.
} 
analyses of postsecondary outcomes and earnings. When examining educational outcomes, the main concern is that the LOS/CS programs could induce students who would have attended an out-of-state or private school to move to the in-state flagship ${ }^{17}$ This will show up as a change in the extensive margin of college enrollment in our data, whereas in actuality such students may be switching across postsecondary schools of similar quality. Of course, these students still would receive the academic services once enrolled as well as the scholarship money. This type of sorting likely would lead us to overstate program impacts, because the students induced to switch schools from the private or out of state sectors probably are better academically-prepared for college and are from less disadvantaged backgrounds than other students at LOS and CS schools.

We address this potential bias in a few ways. First, we note that in the wider population affected by LOS and CS, very few students attend out-of-state or private schools. Indeed, in Texas overall only $18 \%$ of first-time 4 -year college enrollees who were seniors in high school the prior year attend an out-of-state school. While similar statistics for in-state private schools are not available, only $12 \%$ of enrollment in Texas degree granting institutions is in private colleges. Given the low income of students in LOS/CS schools, we would expect these numbers to be far smaller for our population of interest.

Second, we estimate whether the LOS and CS programs have any impact on attending an instate public institution. Thus, the treatment effect is relative to not attending college, attending a private college, or attending an out-of-state college. As we show below, we find little indication that students from LOS or CS schools were more likely to be observed in the postsecondary data after program implementation. Thus, for the programs to induce private/out-of-state students to move to the flagships, there would have to be an offsetting increase in non-college attendance by other treated students, which is very unlikely. Furthermore, we show that increases in enrollment at the flagships are completely offset by an equivalent reduction in attendance in other in-state public colleges.

Attrition bias also can occur in the earnings data due to migration out of Texas. We find some evidence that treated students are less likely to be present in our earnings samples. We

\footnotetext{
${ }^{17}$ Daugherty, Martorell and McFarlin (2014) show that the Top 10\% rule had just such an effect on student college-going in a low-income district.
} 
address any biases from such differential attrition in two ways. First, we test whether attending an LOS or CS school "affects" predetermined student characteristics in the earnings samples relative to students in comparison high schools. Second, we generate predicted earnings of students based on their high school characteristics and test whether the LOS and CS programs change the predicted earnings of those not in the earnings data. We find no evidence that the targeted recruitment programs generate differences in pretreatment characteristics for students in the earnings sample. Our results also indicate that those differentially attriting from the earnings sample due to LOS/CS exposure have higher predicted earnings based on the large set of pre-collegiate characteristics we observe. These tests indicate that our earnings estimates likely do not suffer from attrition bias or, at worst, that our estimates are attenuated due to the differential attrition of those with high predicted earnings.

\section{Methodology}

Our methodological approach to examining the effect of the LOS/CS programs on student college choice, academic outcomes and labor market earnings is to estimate difference-in-differences models in which we compare changes in outcomes among cohorts of students when their school becomes treated to changes among cohorts of students in observationally-similar schools that are not treated. As discussed above, the LOS and CS programs are most likely to affect higherability students. We therefore restrict the analysis to students who are in the top $30 \%$ of their high school class in a given year according to the ability index discussed in Section 3 . We focus on the top $30 \%$ of students rather than the top $10 \%$ because our ability index is an imperfect proxy for class rank. The top 30\% of students accurately captures the large majority of groups that are potentially eligible for enrollment in a state flagship from schools in our sample. This feature of the data is highlighted in Figure 3, which shows enrollment in UT-Austin from LOS-targeted schools and in TAMU from CS-targeted schools both before and after program implementation. The vast majority of enrollees in the flagships are in the top three deciles of the achievement distribution in those schools.

Figure 3 clearly demonstrates that the LOS program positively affected the likelihood of enrollment at UT-Austin among students in treated high schools. Prior to the program's im- 
plementation (1996-1998), enrollment at UT-Austin among college attendees from high schools that would later be treated by the LOS program was below enrollment among students at observationally-similar untreated schools. After the program is implemented, enrollment increases much more in LOS schools than in the comparison schools, especially in the top three deciles where we focus our analysis. In the bottom panel, the enrollment patterns at Texas A\&M surrounding the implementation of the CS program are quite different. Here, Texas A\&M enrollment from the schools that will receive the CS treatment differs little from comparison schools in the pre-CS period except in the ninth decile, where comparison enrollment decreases, and the tenth, where it increases relative to treated schools. The drop-off in top decile enrollment is likely due to students from high schools with both programs preferring UT-Austin 18

In order to estimate the causal effect of the LOS and CS programs on college and labor market outcomes, we use a difference-in-differences model that allows us to identify intentionto-treat effects of the LOS and CS programs. Starting with LOS, we estimate the following equation using LOS-treated schools and a sample of comparison schools that are similar to the LOS schools in the observed characteristics used by UT-Austin to determine treatment eligibility.

$$
Y_{i j t}=\alpha+\beta_{1} L O S_{-} S_{c h o o l}+\beta_{2} L O S \& C S_{-} S c h o o l_{j t}+X_{i j t} \Gamma+\phi_{j}+\theta_{t}+\varepsilon_{i j t},
$$

where $Y_{i j t}$ is an educational or labor market outcome of interest for student $i$ from high school $j$ who graduates from high school in year $t$, and $X$ is a vector of individual characteristics such as high school test scores, race, gender, and economic disadvantage status 19 The model also contains school fixed effects $\left(\phi_{j}\right)$ and year fixed effects $\left(\theta_{t}\right)$. The school fixed-effects make this equation a difference-in-differences model where the timing of treatment varies by school. The main treatment variable, LOS_School is an indicator for whether the graduating cohort in school $j$ and year $t$ is eligible for LOS. The variable equals zero for students who graduate from schools that will join LOS in the future as well as those in never LOS schools and becomes one when a student's graduating cohort is eligible for LOS scholarships and services if they attend

\footnotetext{
${ }^{18}$ Appendix Figure A-1 shows similar patterns for the sample of high school graduates in the top $30 \%$ of their high school.

${ }^{19}$ Texas considers a student to be economically disadvantaged if he or she is eligible for subsidized school lunches or is enrolled in another state or Federal anti-poverty program.
} 
UT-Austin. Hence, $\beta_{1}$ gives us our estimate for the impact of attending an LOS high school on outcomes of interest. A key restriction in this "LOS sample" is that schools that are only eligible for CS and not eligible for LOS are excluded from the sample. This allows us to include $L O S \& C S \_S c h o o l_{j t}$ as an interaction between the two programs in the model. Nonetheless, our focus is on the main LOS effect; we include the interaction term to avoid contamination of the intention to treat from one program with the effect of the other. Throughout this analysis, standard errors are clustered at the high school level.

For the CS program we estimate a similar model using a sample (the "CS sample") that includes all CS schools as the treatment and a comparison group of schools that are observably similar to the CS schools but do not include any schools that participated in only the LOS program. Hence we estimate

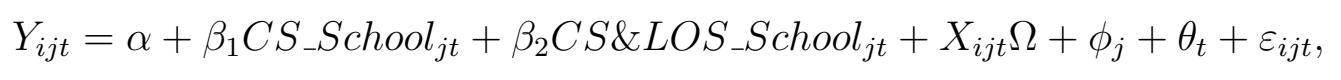

In this case, $\beta_{1}$ provides the causal effect of attending a CS participating high school, while $\beta_{2}$ removes contamination from the LOS program in schools where both programs operate at the same time.

In equations (1) and (2), the treatment parameters show how outcomes change among top $30 \%$ students in LOS/CS schools relative to top $30 \%$ students in untreated schools when the programs are implemented. Hence, the main assumption under which $\beta_{1}$ is identified is that the trends in outcomes among schools not receiving the treatment are accurately measuring counterfactual trends among the treated schools. This identification assumption is potentially strong, especially since the programs are targeted at low-income schools that could have substantially different trends than non-LOS/CS schools absent the treatment.

To make this identification assumption more plausible in our context, we restrict the set of untreated schools to those high schools with common support among key observable characteristics that determine treatment. Using data from the 1996-1998 school years (which is before either program was implemented but includes implementation of the Top 10\% rule), we estimate separate logit regressions of the likelihood a high school becomes an LOS or a CS school as a function of quadratic polynomials in the following school-level characteristics: 
percent enrolling in the targeted flagship in 1996, 1997 and 1998, percent economically disadvantaged, percent black, and percent Hispanic. The first variable accounts for recent trends in under-representation at the specific flagship institution (UT-Austin or TAMU) by measuring how many students actually enroll in the pre-treatment period, a key factor in determining eligibility. ${ }^{20}$ The last three variables account for the socioeconomic makeup of students in the schools that also are important determinants of whether a school receives the LOS or CS program. We use this model to calculate propensity scores that show the likelihood a given high school is treated by each program. The logit regression coefficient estimates are shown in Online Appendix Table A-2.

We first drop all treated schools with a predicted treatment likelihood higher than the highest control school and then drop all schools that have propensity scores less than 0.2 to generate a common support sample that will more accurately account for counterfactual trends. We construct this sample separately for the LOS treatment and for the CS treatment, and the resulting untreated schools together with the treated schools constitute the LOS sample and the CS sample, respectively. Thus, our trimmed common support samples are comprised of a set of schools that have broadly similar likelihoods of being treated based on their observable characteristics ${ }^{21}$ Figure 4 shows the propensity score densities for treated and control schools by likelihood bin, separately for UT-Austin (LOS) and Texas A\&M (CS). In the figure, we have excluded the large mass of control schools with propensity scores below 0.2 as they dominate the graph if included. Ostensibly, we are excluding a large set of high schools that serve higherSES students and that have no probability of being selected for the LOS/CS treatments. As the figures demonstrate, there also are several treated schools that have a predicted likelihood of treatment that is greater than any control school. These schools are excluded from the main analysis because they are sufficiently different from any comparison school that it makes the identification assumptions that underly our estimator more difficult to support.

Throughout the study, we focus on samples that restrict to college attendees who are in the top $30 \%$ of their high school class as measured by our achievement index, as these are the

\footnotetext{
${ }^{20}$ While the CS program does not specifically state what metrics they use to select schools, they do say in their handbook that the program is intended to "to increase the number of enrolled and retained students from under-represented Texas high schools." The LOS program specifically states that they target high schools where sending of ACT and SAT score reports to UT-Austin are low. Unfortunately, we do not have data on score reporting and thus we use actual enrollment history as a proxy.

${ }^{21}$ We have also conducted our analyses using samples that drop control schools below the lowest treated schools and samples that trim at a propensity score of 0.1 . In both cases we get similar results.
} 
students who are most likely to be impacted by the programs. We show below that there is no impact on the college attendance margin, so there is little concern that the composition of our college enrollment sample is endogenous with respect to the LOS or CS treatments. For the sake of completeness, however we also provide the full set of estimates for a sample of all high school graduates in the top $30 \%$ of their high school class in the online appendix. As expected, the results for the high school grad sample are attenuated since we are increasing the number of students who contribute to the intention to treat estimate without actually increasing treatment propensity. Nonetheless, in most cases, the estimates maintain the same direction with the same level of statistical significance as the college attendee sample.

Table 2 shows demographic and measured high school academic achievement characteristics for top 30\% students in our trimmed common support samples who attend college. For both the LOS and CS estimation samples, students in the comparison schools are higher achieving and more likely to be white. However, in the LOS sample the comparison schools are more economically disadvantaged. These samples are much more similar to each other than they are to schools that are not in the common support. Indeed, in both the treated and control groups, the majority of students are African American or Hispanic, a large proportion are at risk of dropping out of high school, and they exhibit high rates of economic disadvantage. For comparison, in the 2000-01 school year, the average economic disadvantage rate in Texas for high school students was $36 \%$.

Table 3 provides similar comparisons for our outcomes of interest. First, we consider the student's initial college of attendance. Within this sample of high-achieving college attendees, very few students attend the flagships (as was evident in Figure 3). Only 6\%-9\% of top 30\% graduates from treated schools attend either UT or TAMU. Many attend emerging research universities or other 4-year schools, and almost half of all the college attendees are observed first attending a two-year school. Transfer rates are quite high, at almost 40\%, and 6-year BA attainment rates are low at under 25\%. Outcomes in comparison schools tend to be slightly better than in treatment schools, but the differences are not large. Overall, Tables 2 and 3 highlight that the LOS and CS schools are targeting schools that serve a large proportion of disadvantaged students who have low postsecondary investment rates and poor postsecondary 
outcomes.

The differences in demographic characteristics among the treated and comparison schools is not a threat to identification as long as they are fixed. A key element to establishing the validity of a difference-in-differences identification strategy is being able to show that exogenous observed characteristics are not affected by the treatment. In Table 4, we provide balance tests using equations (1) and (2) for the college attendee samples in which we exclude all characteristics in $X$ and use each observable shown in the column header as a dependent variable. Panel A shows results for LOS while Panel B shows the results for CS. The estimates for the LOS and CS main effects are universally small and statistically insignificant in both estimation samples while for the interaction effects only gifted and talented status in the LOS sample is statistically significant. These results support our difference-in-differences identification strategy as there is little indication of the program implementations correlating with demographic or performance changes in high schools 22

Given the targeted nature of these programs, it is important to understand what drives the assignment of high schools to treatment conditional on the observables. Returning to Figures 1 and 2 that show the geographic distribution of LOS and CS schools, respectively, as well as the comparison schools, we see that much of the treatment variation is geographic. The LOS and CS programs were targeted towards urban high schools in the largest cities in Texas. ${ }^{23}$ Thus, there are observationally equivalent schools located outside these cities that comprise most of the control groups. There are some comparison schools in these cities as well but they tend to be located outside the urban centers and reflect the fact that these programs faced budget constraints that allowed them only to treat a subset of qualifying schools. Figures 1 and 2 suggest that there is plausibly-exogenous variation in treatment status based on geography that allows us to identify $\beta_{1}$ in equations (1) and (2). While in our main estimates we do not explicitly take advantage of this, we provide specification checks that restrict our comparison schools so that they are not in districts or counties with treated schools and find similar results.

While our trimmed common support sample makes the common trends assumption more likely to hold, it is important to provide direct evidence on the validity of this assumption.

\footnotetext{
${ }^{22}$ Estimates for the top $30 \%$ high school graduates are very similar and are shown in Appendix Table A-3.

${ }^{23} \mathrm{~A}$ former administrator of the LOS program told us that they restricted to schools in close proximity to UT-Austin's recruitment centers, which were located only in major cities.
} 
Thus, we estimate event study models in which we interact indicators for whether a school will ever be treated by the LOS or CS programs with each calendar year and estimate the impacts on our outcomes of interest. This allows us to test explicitly for the existence of differential pre-treatment trends in these outcomes. As we describe in detail below, we find no evidence such trends exist for any outcome, which strongly supports our empirical strategy.

The second main assumption underlying our difference-in-difference strategy is that there must not be external shocks in 1999-2002 that affected CS/LOS schools differently from the control schools. It is difficult to test this assumption with our data. Of particular concern is the imposition of the Top $10 \%$ rule in 1998. As a result of this rule, most admissions to the flagship schools were from the top $10 \%$ of a class. Equations (1) and (2) are identified under the assumption that the top $30 \%$ in the treated and control schools (as measured by achievement) are similarly affected by the Top $10 \%$ rule. This assumption is made more palatable by the use of the trimmed common support sample, since both treated and control schools serve lowSES students with low historical flagship enrollment rates. However, our event study estimates also shed light on any bias from the Top 10\% rule as this law went into effect in 1998 while the LOS/CS treatments were not rolled out until 1999-2000. We therefore should see effects in 1998 if the Top 10\% Rule is driving our estimates, but as shown below the time pattern of effects much more closely matches the timing of the LOS/CS roll-out than the Top 10\% rule implementation. Furthermore, we show that the LOS program does not positively affect enrollment in Texas A\&M and the CS program does not positively affect enrollment at UTAustin. If our results were simply picking up differential flagship enrollment increases due to the top $10 \%$ rule, we would not expect to see such a pattern.

Equations (1) and (2) are designed to identify intent-to-treat (ITT) parameters. That is, $\beta_{1}$ shows the effect of being exposed to the LOS or CS intervention by being in a treated high school (or by being a high-performing student in a treated high school). This is primarily out of necessity as there are multiple treatments involved in the programs and it is unclear which students get which treatment. From a policy perspective, the ITT is an extremely important parameter because universities cannot compel take-up. In addition, there can be spillover effects onto students who do not receive a LOS/CS scholarship, particularly from the 
recruitment part of the programs. Thus, from the policymaker's standpoint, the ITT is the most relevant parameter and it is the one our empirical strategy is best designed to estimate. We therefore focus on the ITT parameter throughout the study. We also provide some context to the ITT estimates by calculating back of the envelope estimates of the effect of treatment on the treated under a broad definition of what constitutes treatment in this context.

\section{Results}

\subsection{Enrollment Effects of LOS and CS}

Estimates of equations (1) and (2) using college enrollment outcomes as the dependent variable are shown in Table 5. Panel A contains the results for the LOS program and Panel B shows the estimates for the CS program. Each set of two estimates in a column is from a separate regression.

In Panel A of column (1), we show the effect of the LOS and CS treatments on attending any public college in Texas using the sample of high school graduates. Recall that we only have data on students who attend public colleges in Texas; if the programs induce students to enter the public university system from other places - private schools, out-of-state schools, or from not attending college at all - it would appear as an increase in college enrollment in our data. The estimates in Panel A show no evidence of a change in enrollment in a public Texas 2-year or 4-year college or university due to the LOS program (first row). The estimates in the second row, which represent the differential impact of a school being eligible for CS in addition to LOS, also show no statistically significant effect. Similarly in Panel (B), the estimates in column (1) are small and are not statistically insignificant at even the $10 \%$ level. From these results, we conclude that the likelihood of attending any Texas public college is unaffected by the LOS/CS treatments, which negates worries about selection into the college-going sample. As a result, we focus on the college attendee sample for the remainder of the analysis. Full results for high school graduates are provided in the online appendix. ${ }^{24}$

One of the main goals of the LOS and CS programs is to induce more students from the targeted low income high schools to enroll in the flagships. Our results show that while the

\footnotetext{
${ }^{24}$ These results are included in Online Appendix Tables A-4,A-6, A-7, A-9 and A-10.
} 
LOS program was very successful in this goal, the CS program had little impact on enrollment. Columns (2) and (3) of Table 5 provide estimates of the impact of attending an LOS or CS high school on enrollment at a flagship. We find an increase in attendance of 2.2 percentage points in UT-Austin due to LOS exposure. In the pre-treatment years, the average UT-Austin enrollment rate in our sample was 0.027 ; hence the LOS program increased UT-Austin enrollment by $81 \%$. However, as column (2) demonstrates, there was no effect of LOS on TAMU enrollment. This is an important finding for two reasons. First, if the top 10\% rule caused these enrollment increases, we would expect both UT-Austin and Texas A\&M enrollment to increase, contrary to what the data indicate. Second, the LOS program did not simply shift students across flagships but rather caused a substantial increase in college quality. This point is further highlighted by the remaining columns of Table 5. Nearly all of the increase in UT-Austin enrollment came from students who would have enrolled in the emerging research universities (ERUs). While these students would have attended four-year schools in the absence of the program, they nonetheless experience a substantial upgrade in college quality. As Table 1 shows, UT-Austin has more resources, stronger peer quality, and better measured outcomes than the ERUs ${ }^{25}$

In contrast to the enrollment effect of the LOS program, Panel (B) indicates that the CS program did not increase enrollment at Texas A\&M. Schools that received both treatments experienced an increase in enrollment at UT-Austin of 2.2 percentage points, which is in line with the results in panel (A) indicating that this result is due to the LOS rather than the CS program ${ }^{26}$ There is some indication of resorting among other four-year schools, but given that it is hard to explain why the CS program would induce such behavior, we believe this result to be spurious. Hence, it appears that the CS program was ineffective at altering the enrollment behavior of students in treated schools. The differences across programs is likely due to their differences in scope and the amount of resources put into recruiting students from these high schools. However, we lack the data to be able to test these hypotheses directly.

A core identification assumption embedded in equations (1) and (2) is that the treatment and comparison schools are trending similarly prior to the treatment. In order to provide evidence in support of this assumption, Figure 5 shows event study estimates of enrolling in

\footnotetext{
${ }^{25}$ Appendix Table A-4 contains enrollment estimates for the high school graduate sample. The estimates are qualitatively and quantitatively similar to those shown in Table 5: the effect on UT-Austin enrollment is $82 \%$ of the pre-treatment enrollment rate.

${ }^{26}$ Recall that the samples in Panels (A) and (B) are different due to different trimmed common support comparison groups, which is why the estimates for the jointly-treated schools are not the same across panels.
} 
UT-Austin and Texas A\&M for each of the respective top-30\% college-going samples. For both programs, there is no evidence of a differential upward trend in the specified flagship's enrollment prior to treatment. Consistent with the results in Table 5, there is a clear increase in UT-Austin enrollment after 1999, when the LOS program began in some schools, that is not predictable from pre-treatment trends. However, there is no evidence of an increase in Texas A\&M enrollment after 2000 when the CS implementation begins. Furthermore, these results suggest that the Top $10 \%$ rule is not a serious confounder in this setup, as there is no apparent increase in enrollment in either flagship in 1998 (the first year of the Top 10\% rule). That is, any differential changes in enrollment between treated and untreated schools start to occur in 2000 after LOS was implemented, not in 1998 when Texas Top 10\% rule was implemented. Overall, Figure 5 is consistent with the identification assumptions underlying our difference-indifferences. Appendix Figure A-2 shows event study estimates for enrollment effects of the LOS program at schools other than UT-Austin. There is little evidence of pre-treatment trends for any enrollment outcome, and the post-treatment estimates match those in Table 5 closely.

Given that the CS program did not impact college enrollment and both the scope of the services provided and access to those services was smaller than LOS, ex-ante, one would predict the CS program would not have large effects on collegiate and labor market outcomes. Indeed, in our analysis of the CS program, we do not find a statistically significant effect on any outcome we investigate. These results are sufficiently precise that we conclude the CS program had no impact on flagship enrollment, graduation rates, major choice, or earnings. As a result, we focus on the LOS program for the remainder of the analysis, while estimates for the CS program are provided in the online appendix.27

\subsection{Graduation and Major Choice Effects of LOS}

Thus far, our results indicate that students in LOS schools experienced a substantial increase in college quality by shifting from lower-resource public schools to UT-Austin. The prior literature on the educational returns to college quality suggest that this intervention should lead to higher BA receipt (Cohodes and Goodman 2014; Bound, Lovenheim and Turner 2010). Further, the LOS program provides a number of services to students like peer mentoring that also have been

\footnotetext{
${ }^{27}$ Online appendix tables A-4, A-5, A-7, A-8 and A-10 contain results for the CS program.
} 
shown to improve student performance (Angrist, Lang and Oreopolous 2009). In Panel (A) of Table 6, we examine how the LOS program affected graduation from UT-Austin along with four-, six-, and eight-year BA completion, attendance at a public Texas graduate school, and transferring behavior between public TX institutions. In column (1), we show that the LOS treatment led to a 1.7 percentage point increase in the likelihood of graduating from UT-Austin within 6 years. This is an $87 \%$ increase relative to the pre-treatment mean and the graduation effects are about $77 \%$ of the enrollment effects in Table 5. This suggests that the program was very effective at getting the marginal attendees to graduate from UT-Austin. However, the academic support services and scholarship funds may have increased graduation rates among treated students who would have attended UT-Austin even in the absence of the program, which means we cannot necessarily attribute the entire increase in UT-Austin graduation to the marginal attendees. Columns (2)-(6) provide information on collegiate outcomes that shed additional light on this question. The LOS treatment did not affect four, six, or eight-year graduation rates overall in Texas nor did the program significantly affect public graduate school attendance (though we cannot observe any impacts on graduate school enrollment at out-ofstate or private graduate schools). It also did not affect the likelihood of students transferring between public Texas institutions, which is important because it indicates that marginal UTAustin students did not transfer away to other schools after their initial enrollment.

Figure 6 shows event studies of the main graduation outcomes we analyze. We find no evidence of pre-treatment trends that would bias our results, and in all cases the timing of the effects line up closely with when the LOS policy was implemented. Again, this provides evidence that the impacts we estimate are coming from the LOS treatment rather than from other policies such as the top $10 \%$ rule that were in place during this time period.

Table 7 provides a more direct analysis of the effect of the LOS program on the paths students took through the postsecondary system. We categorize students into mutually exclusive groups by their first college type attended (UT, TAMU, ERU, Other 4 Year, and 2 Year) and their eventual collegiate outcome (graduate from a flagship, graduate from a non-flagship public 4year school, and do not graduate from a public 4-year institution) ${ }^{28}$ Each column and panel

\footnotetext{
${ }^{28}$ We pool the flagships together when we look at graduation because there is little transferring across flagships in Texas (Andrews, $\mathrm{Li}$ and Lovenheim 2014). We further pool the two non-flagship four-year school types together to keep the number of outcomes we are analyzing to a manageable size.
} 
combination comes from a different estimation of equation (1), where the dependent variable is an indicator for students taking the given path. For example, in the first panel column (1) shows the effect of the LOS program on the likelihood students begin at UT-Austin and graduate from a flagship. The estimates in column (2) in the third panel show the effect of LOS on the likelihood a student first enrolled in an ERU and then graduated from a non-flagship four-year school. All graduation outcomes are within six years.

The estimates in Table 7 suggest that the LOS program's main effect on college enrollment behavior was to increase the proportion of students who both enroll in and graduate from UTAustin. These students are mostly drawn from a group that would have enrolled in an ERU, some of whom would not have graduated within 6 years, as shown in the third panel. There also is a small subset of students induced to attend UT-Austin who do not obtain a degree within 6 years, but this effect is less than half the size of the UT graduation effect. Overall, these results indicate that the LOS program induced many students who otherwise would have attended a non-flagship research university to both enroll in and graduate from UT-Austin. The slight increase in the UT-grad path relative to ERU-grad and ERU-non-grad paths reflects the small and insignificant positive 6-year graduation estimate in Table 6. This finding runs counter to what one would expect if the students are academically mismatched to the more demanding educational environment. It is important to emphasize, however, that this is not a direct test of mismatch as the students attending these colleges also are receiving enhanced academic services. One policy-relevant interpretation of these results is that these academic services are sufficient to overcome any academic mismatch faced by the treated students.

Another prediction of mismatch theory is that under-prepared students will gravitate to easier majors when they are overmatched. In Panel (B) of Table 6, we examine whether the LOS program induces students to alter their chosen course of study. We focus in this table on the student's "final major," which is either the major at graduation or the last observed major for students who do not graduate from a public Texas college by the end of our sample period. LOS treatment increases the proportion of students majoring in social sciences and in arts and humanities primarily at the expense of students enrolled in "other" unclassified majors. This other category is comprised of education along with mainly vocational and technical 
support majors. Importantly, there is no statistically (or economically) significant effect on the proportion of students majoring in STEM. Hence, LOS does not reduce the average difficulty of the majors students choose. There is growing evidence that mismatch leads students to shift to easier majors (Arcidiacono, Aucejo and Hotz 2013; Arcidiacono, Aucejo and Spenner 2012). The results in Table 6 show little evidence to support such mismatch effects for high achievers in this setting, which possibly is due to the student support services included in the program ${ }^{29}$ That students are not majoring in easier subjects but are attending and graduating from more elite schools suggests the LOS program led to large increases in human capital accumulation.

\subsection{Earnings Impacts of LOS}

The large returns to college quality (Andrews, Li and Lovenheim 2016; Hoekstra 2009; Black and Smith 2004, 2006; Brewer, Eide and Ehrenberg 1999) suggest that the LOS intervention should increase earnings after college. Even so, college quality improvements only affect a subset of treated students. Many more students are provided assistance through additional financial aid, which might free up time to focus on their studies instead of working while in college. Furthermore, all students from an LOS high school who attend UT-Austin receive access to the suite of academic support, mentoring, and networking services provided by the program. Hence, there are a number of avenues through which the LOS program could affect students' earnings.

In Table 8, we examine the effect of the LOS program on earnings using the adjusted log quarterly earnings measures discussed in Section $33^{30}$ We examine all earnings $6+$ years after high school, 10+ years after high school and 12+ years after high school as long as the worker has at least 5 quarters of earnings in the relevant time frame 31 Earnings estimates $12+$ years after high school graduation are particularly important as the former students would have typically reached at least an age of 30 in this group. This is close to the age when cross sectional earnings

\footnotetext{
${ }^{29}$ Arcidiacono, Aucejo, Coate and Hotz (2014) argue that a substantial amount - and possibly a majority - of the increase in minority graduation rates they find after California's affirmative action ban was due to behavioral responses that include expanded services.

${ }^{30}$ Online Appendix Tables A-8 through A-10 contain results for the CS program and for the high school graduate sample for the LOS program.

${ }^{31}$ In Online Appendix Table A-11 we provide estimates using different sample restrictions for the earnings sample. While our primary sample restricts to individuals with at least 5 quarters of at least $\$ 100$ of earnings in the specified time frames, we also present estimates that loosen this restriction to 3 quarters, that restrict to calendar years with $\$ 100$ or more in each quarter, and that do not restrict to a minimum number of quarters. Estimates in these cases are qualitatively and quantitatively similar to those provided in Table 8.
} 
become most predictive of lifetime earnings (Haider and Solon, 2006).

In the even columns, we provide ITT earnings effects from the LOS program. Interestingly, while the earnings in the $6+$ years sample are small and not statistically significantly different from zero at conventional levels, the estimates grow as we move to later samples. In the $10+$ years sample, the estimated earnings impact is a statistically insignificant $2 \%$. Crucially, however, when we focus on $12+$ years earnings, which are more likely to be reflective of lifetime earnings, we see a large and statistically significant effect of $4 \%$. There are two important aspects of interpretation of this result. First, the gradual increase in wage returns as the LOS students age is notable as it suggests that the effects come from actual skill development and human capital improvements rather than simply better signaling from attending the higher quality school. If the latter were true, then we would expect the wage returns to show up immediately. The late development of the earnings returns suggest that the programs make the students more likely to succeed in their long-run career paths rather than simply getting them higher paying jobs at the outset. Second, we can use this information to develop a back of the envelope estimate of the treatment effect. While it is tempting to simply inflate the returns by the 2.2 percentage point increase in enrollment at UT-Austin, this would not be appropriate due to the multifaceted nature of the intervention. In fact, every student from an LOS eligible school who attends UT-Austin receives some treatment in the form of services, and most receive financial support. Infra-marginal UT-Austin attendees are treated in addition to the students who are induced to change institutions. Further, students who are on the attendance margin are not only more likely to attend the flagship but they are also more likely to graduate from the flagship, increasing the potential returns. With that in mind, we can calculate an implied treatment effect by dividing the earnings impact by the total UT enrollment rate for top $30 \%$ students from LOS schools after the schools become eligible. With $5.6 \%$ of students in this subsample attending UT-Austin, this leads to a treatment effect on the treated of approximately 70\%. This is a particularly large earnings effect when compared to prior estimates of the impact of college quality on earnings. Below, we explain why this is a plausible earnings impact for the population of high achieving low-income minorities targeted by the LOS program.

In the odd-numbered columns of Table 8, we estimate whether being in an LOS high school 
affects the likelihood that one appears in the earnings data. Across the time frames, there is a 1.5 to 1.9 percentage point reduction in being observed associated with attending an LOS high school, and these estimates are statistically significant in the $6+$ and $12+$ earnings samples. Thus, there appears to be some differential attrition from the sample. While this indicates that the earnings estimates could be biased, we have good reason to believe that our results are, at worst, attenuated by any differential attrition. This makes our results conservative lower bounds. To more closely examine the attrition shown in Table 8, we test for balance of pre-determined characteristics in the earnings samples as we do for the full sample in Table 4. These results are provided in Online Appendix Table A-12, and like those in Table 4, they show no statistically significant effects except G\&T for the interaction term. The estimates in Table A-12 provides evidence that there is little attrition bias.

Nonetheless, when we consider the types of workers who are induced to attrit by LOS we conclude that a worst case scenario is that we underestimate the earnings effect. The first group includes those induced to attend graduate school. While we do not find a statistically significant increase in public graduate school attendance, the estimate in Table 6 is 0.008 - about $1 / 2$ of the attrition effect. Further, there could be increases in attendance at private and out-ofstate graduate programs. Nonetheless, in the $12+$ year sample even those getting postgraduate degrees would likely have completed their schooling. Hence, more people probably fall into the second group, which is comprised of those who take jobs out of state. ${ }^{32}$ Graduating from UT-Austin gives students access to a more national labor market, and thus it makes sense that there is some attrition from the earnings data due to the treatment. Both of these arguments suggest it will be the most highly-skilled and the highest earnings-potential students who exit the earnings sample. To test this hypothesis, we estimate whether there is an LOS "effect" on the predicted earnings of students who do not show up in the earnings sample. Specifically, we predict earnings for those in the sample by regressing $\ln$ (earnings) on high school test scores and demographics and then estimate model (1) using the predicted earnings as the outcome for those who are not observed in the earnings data. In Online Appendix Table A-13, we show that the earnings attriters exposed to LOS have $4 \%$ higher potential earnings. This indicates that

\footnotetext{
${ }^{32} \mathrm{~A}$ potential third group is made up of the unemployed. However, it is very unlikely that the differential attrition is due to LOS increasing unemployment, as the pattern of non-earnings results suggest students will become less likely to be unemployed. The observed shifts in majors is not expected to increase unemployment, and we do not see any negative impacts on graduation. The shift towards graduating from higher quality institutions (specifically UT-Austin) in particular is expected to reduce unemployment.
} 
students who do not have observed earnings due to LOS exposure have higher potential earnings than comparison attriters and hence any bias in our estimates would lead us to underestimate earnings effects.

\subsection{Specification Checks and Heterogeneous Impacts of LOS}

In Table 9, we provide specification checks that address additional potential concerns about the validity of our estimates. First, in our estimates we do not place geographic restrictions on the comparison schools. This leaves open the possibility that we include comparison schools from the same districts as LOS schools. These comparison schools could have been chosen based on unobserved characteristics that are not accounted for in our propensity scores. Further, those estimates do not take full advantage of the plausibly exogenous variation generated by the geographic limitations placed on the programs. Nonetheless, we note that in practice we have very few comparison schools from the same districts and counties as treated schools and a substantial number of comparison schools became LOS schools after our analysis period when the program expanded to other parts of Texas, particularly El Paso and the Rio Grande Valley. In panels $\mathrm{A}$ and $\mathrm{B}$ of the table, we explicitly utilize the exogenous geographic variation generated by the program implementation restrictions by dropping comparison schools in the same school districts and counties as the LOS treated schools, respectively. In both cases, the results are nearly identical to our baseline estimates. The third panel of Table 9 checks an opposing concern which is that, if our comparison schools are not in the same areas as the LOS schools, then perhaps we are picking up an urban/rural distinction rather than an LOS effect. Since we have so few comparison schools in the major metropolitan areas of Houston, Dallas and San Antonio where most LOS schools are located, we cannot test this directly. Instead, we estimate models that restrict the sample to only include schools in Census designated Metropolitan Statistical Areas (MSA) with populations greater than 300,000 people to ensure that all of the comparison schools are in relatively urban areas. Once again, the results are nearly identical to baseline.

Table 10 provides some heterogeneity analyses to look at whether there are differences by gender and economic status. Since $90 \%$ of the students in LOS schools are black or Hispanic we do not provide results broken down by race. In Panels A and B, we first look at whether the 
LOS impacts differ based on the income of the students by looking specifically at students who qualify for free or reduced-price lunch. While the LOS program targeted low income schools, a substantial number of students in these schools came from families with incomes that, while modest, were not impoverished. This is reflected in the rates of economic disadvantage amongst high school graduates from LOS schools of 50\%.33 Further, while eligible schools were targeted based on average student income, an individual's income was not a factor in the receipt of a scholarship. For most outcomes, the effects differ little by economic status. Students become more likely to enroll and graduate from UT-Austin at the same rate, while there is no significant impact on 6-year graduation rates in either case. When we turn to earnings estimates, some differences emerge. First, both $10+$ and $12+$ year earnings estimates are larger for economically disadvantaged students. While the differences are not statistically significantly different, they nonetheless are consistent with lower income students being particularly well positioned to benefit from the program in the long run. It is also worth noting that there is no attrition impact for lower income students, while there is a significant one for higher income students. This is also consistent with LOS inducing students to move out-of-state, as higher income students would have more resources and less need to stay at home to, for example, take care of family members. Hence, the earnings effects for non-disadvantaged students may be underestimated.

When we turn to panels $\mathrm{C}$ and D that look at gender heterogeneity, we see marked differences between men and women. Virtually all of the increases we see in UT-Austin enrollment, UTAustin graduation and earnings accrue to women. Enrollment amongst women at UT-Austin increases by 4 percentage points, a 164\% increase relative to the pre-LOS mean for women, and graduation increases by 2.6 percentage points, a $124 \%$ increase relative to the pre-LOS mean for women. For earnings, we see a $6.1 \%$ increase. With a post-LOS enrollment rate in UT-Austin of 0.058 this suggests that the treatment effect for women's earnings is $105 \%$. For men, on the other hand, while all of these estimates are positive, none is statistically significantly different from zero at even the $10 \%$ level and all are small in magnitude.

It is difficult to explain the different effects of the LOS program on men and women, and unfortunately, our data are not well equipped to do so. However, there is some evidence

\footnotetext{
${ }^{33}$ It is likely that this measure understates the true economic disadvantage rate of the school as students in high school are often reported to be disadvantaged at lower rates than students in elementary schools due to lower take-up.
} 
from prior research that can provide context to our findings. In an experiment that provided additional academic support and/or financial incentives to students in college Angrist, Lang and Oreopoulos (2009) find that women were more likely to take up the academic supports and, when the supports were combined with incentives, performed better academically while men did not. This indicates that it is possible that women were more attracted to the supports provided by LOS and more likely to use them when enrolled. There also is evidence of larger benefits for women in other education-related interventions. For example, Deming et al. (2014) show that attending a higher quality high school school leads to substantially larger increases in college attendance for women but not for men. Women also see improvement in grades and college preparatory course taking while men do not. As another example, the Moving to Opportunity housing voucher experiment saw larger improvements for women in terms of crime, health, and educational attainment (Ludwig et al. 2013; Kling, Liebman, and Katz 2007; Kling, Ludwig, and Katz 2005). Finally, Anderson (2008) shows that randomized early childhood education interventions generated large short and long term effects for girls but not for boys.

\section{Discussion}

Overall our results show that there are large increases in enrollment in and graduation from UT-Austin from the LOS program and large earnings returns, while there are no effects of the CS program for Texas A\&M University. Two questions that emerge from our findings are: why was the LOS program more successful than CS and why are the LOS earnings effects so large?

There are a number of reasons why we might expect the CS program to be less effective than LOS. One key difference is that it appears that the service component of the interventions could be quite important in helping students get through the more academically-rigorous flagships. The services provided by LOS and CS differed quite substantially. The focus of CS services was on professional and social development - providing students with interviewing and job search advice, building communities and networks, and community service. In terms of academic supports, students were only provided faculty mentors (with whom, according to current program rules, students are only required to meet twice in their sophomore year) and special academic advising was only provided if a student's GPA fell below 2.25. The LOS support 
services, however, while also building a community of similar students, were far more focused on academic supports. These included free tutoring, peer mentoring, special small sections of freshman courses, and guaranteed on-campus residence.

However, the difference in service intensity does not explain why LOS was more successful at attracting new students to UT-Austin than CS was at attracting new students to Texas A\&M. One potential explanation for this is that our sample if urban, heavily minority students may have been reluctant to attend TAMU, which is located in a rural and less diverse part of the state than UT-Austin and many other 4-year schools. During the study period, UT-Austin also had a larger minority student population than Texas A\&M Another potential explanation is that CS targeted inframarginal students. This is particularly likely due to the Top $10 \%$ rule as most, and possibly all, of the students offered CS scholarships were also (at least implicitly) admitted to UT-Austin as well. Hence, the CS scholarships may have targeted students who were already set on attending either institution and the program was not effective at changing their decision.

The second remaining question is whether the large earnings effects for LOS are plausible. Overall, the treatment effect on the treated from the intervention (including at least one of services, scholarship, and/or switching institutions) is an approximately $70 \%$ increase in earnings. While we are not aware of any evidence of how academic supports in college affect later life earnings, this estimate is larger than estimates of the returns to attending an elite institution relative to other institutions that range from 20\% to 54\% (Anelli, 2015; Hoekstra, 2009). The individuals studied in those papers are quite different from our sample of low income students who are primarily minorities. Hoekstra (2009) is only able to examine white students and is not able to break down estimates by income. Anelli (2015) looks at an elite and expensive private university in Milan, Italy and also does not break down results by income level. Further, in both studies identification comes from admission thresholds, which makes the students academically marginal. In the LOS context, the students are low income, primarily minorities, and are high ability. The mean test scores of LOS students who enroll in UT are about 0.8 standard deviations above that of the average Texas high school student, while the average

\footnotetext{
${ }^{34}$ In 2000, the total population of College Station, TX which houses Texas A\&M was just 68,000 with a racial composition of $82 \%$ white and $10 \%$ Hispanic. Austin, TX which houses UT-Austin had a population of 656,000 with a racial composition that was $68 \%$ white and $31 \%$ Hispanic. In terms of university racial statistics, in 2000 first-time freshmen at UT-Austin were $4 \%$ black and $15 \%$ Hispanic, while at TAMU those figures were $3 \%$ and 9\%, respectively (Kain, O'Brien, Jargowsky 2015).
} 
for all Texas high school students who enroll in UT is around 0.85 standard deviations. The average LOS school attendee at UT is well within the $2^{\text {nd }}$ quartile of all UT-Austin enrollees from Texas in terms of high school test scores. Thus, LOS students are academically better matched for UT-Austin than the students in RD studies of the returns to college quality. As a result, we argue that our estimates suggest that low-income, high ability students (particularly women) are primed to benefit substantially more than other students from increased college quality and academic support services in college.

In addition, the apparent change in college quality is far larger in our analysis than in Hoekstra (2009). On average the most likely alternative institutions (Hoekstra cannot observe actual enrollment in other institutions) had per student spending at $91 \%$ of the flagship level and SAT scores 95 points lower than the flagships. Returning to Table 1 and comparing UT-Austin to the Emerging Research Universities where LOS students would have attended otherwise, we see that the ERU's have instructional spending at $46 \%$ of the UT-Austin rate and $75^{\text {th }}$ percentile SAT Scores 249 points lower.

The time path of the earnings returns also is important to highlight. Our estimates in Table 8 increase as we narrow to years further out in the individual's life. In fact, the point estimates more than double when we drop years 6 - 11 after high school graduation. This suggests that the earnings improvements came from skill development rather than simply better signaling and networking opportunities, as we would expect the latter to generate earnings returns earlier in the student's career whereas the former may take time to become valued in the labor market.

\section{Conclusion}

Persistent increases in the college wage premium combined with sluggish growth in collegiate attainment, particularly among students from low-income backgrounds, make it of first-order importance to understand what policies can reduce attainment gaps in higher education across the socioeconomic distribution. Given the evidence of the educational and labor market returns to college quality as well as the low enrollment rates among low-income students at elite schools, policies designed to raise enrollment rates of disadvantaged students at high-quality colleges have the potential to reduce these disparities. Further, it is likely that students from 
disadvantaged backgrounds would benefit from support services that enhance their experience. We study two examples of such policies in Texas, the Longhorn Opportunity and Century Scholars programs, which were designed to address the multitude of disadvantages faced by low-income students in higher education: information, tuition subsidies, and support services once enrolled. These programs were targeted at schools that served large numbers of low-income students and that tended to send few students to University of Texas at Austin (LOS) or Texas A\&M University (CS).

We combine the timing of the implementation of the LOS and CS programs with detailed administrative data from K-12 records, higher education records, and earnings as long as workers remain in Texas and attend a public university. We implement a set of difference-in-difference estimators using trimmed common support samples of treated and comparison schools that compare how the enrollment behavior, educational outcomes, and earnings of high-ability students change when the programs are implemented in targeted high schools.

Our estimates suggest that this type of bundled intervention can generate better outcomes among targeted students. The LOS program induced many students to enroll in UT-Austin instead of lower-resource four-year institutions. This shift towards the flagship provided a large quality upgrade relative to the schools the students would have attended in the absence of the program. High-achieving students affected by the LOS program saw large and statistically significant increases in the likelihood of graduating from UT-Austin, and we find little evidence of academic mismatch in the form of students switching to "easier" majors. We find that the combination of academic support services, financial support, and higher college quality increased the likelihood a student would graduate from UT-Austin and earnings 12 or more years after a student completes high school. These effects are large - enrollment in UT-Austin increases by over $80 \%$ and earnings of treated students (where treatment applies to all UTAustin enrollees from LOS schools, not just those students who change institutions) increases by $70 \%$. Virtually all of the impacts are concentrated among women. The large returns to the program indicate that these high ability, low income, and heavily minority students may be particularly sensitive to improvements in college quality and academic support services.

In contrast to the findings for the LOS program, the CS intervention had no effect on 
enrollment behavior, postsecondary outcomes or labor market outcomes. We argue there are two likely explanation for the differences in these programs. First, the support services provided by CS were focused on professional development rather than academic supports, were less intensive, and were not made as widely available to students from treated high schools. Second, the relatively low minority populations and rural location of Texas A\&M made it an unattractive choice for the targeted students, particularly given that most were also admitted to UT-Austin.

Our analysis cannot determine how much of the impacts we find are due to the change in school quality or the provision of academic supports and financial aid. We thus interpret our estimates as telling us whether a program that provides a full package of services to high-achieving, low-income students that addresses the suite of disadvantages they face in the postsecondary system affects their educational and labor market outcomes. The results suggest that programs like the Longhorn Opportunity Scholarship hold much promise in promoting better postsecondary and labor market outcomes among these students. Furthermore, while it is unclear if the students treated by the program are actually "overmatched" for the state flagships, the results suggest that mismatch problems can be overcome with sufficient support services. Crucially, programs like these and the supports they provide can easily be replicated in any state flagship institution. The estimates for the Century Scholar program, however, provides a cautious note as it is not automatic that such a program will succeed in attracting new students or affecting postsecondary and labor market outcomes. More work focusing on the specific ways in which these programs were implemented and the implications for effectiveness would be of high value in order to better understand how to structure these programs to maximize their positive effects on students. 


\section{References}

[1] Altonji, Joseph G., Erica Blom and Costas Meghir. 2012. "Heterogeneity in Human Capital Investments: High School Curriculum, College Major, and Careers." NBER Working Paper No. 17985.

[2] Anelli, Massimo. 2015. "Returns to Elite College Education: A Quasi-Experimental Analysis" Bocconi University, mimeo.

[3] Anderson, Michael. 2008. "Multiple Inference and Gender Differences in the Effects of Early Intervention: A Reevaluation of the Abecedarian, Perry Preschool, and Early Training Projects" Journal of the American Statistical Association 103(484): 1481-1495.

[4] Andrews, Rodney J., Jing Li and Michael F. Lovenheim. 2016. "Quantile Treatment Effects of College Quality on Earnings." Journal of Human Resources 51(1): 200-238.

[5] Andrews, Rodney J., Jing Li and Michael F. Lovenheim. 2014. "Heterogeneous Paths Through College: Detailed Patterns and Relationships with Graduation and Earnings." Economics of Education Review 42: 93-108.

[6] Andrews, Rodney J., Vimal Ranchhod, and Viji Sathy. 2010. "Estimating the Responsiveness of College Applications to the Likelihood of Acceptance and Financial Assistance: Evidence from Texas." Economics of Education Review 29(1): 104-115.

[7] Angrist, Joshua, Daniel Lang and Philip Oreopoulos. 2009. "Incentives and Services for College Achievement: Evidence from a Randomized Trial" American Economic Journal: Applied Economics 1(1): 136-163

[8] Angrist, Joshua, David Autor, Sally Hudson and Amanda Pallais. 2014. "Leveling Up: Early Results from a Randomized Evaluation of Post-Secondary Aid." NBER Working Paper No. 20800.

[9] Arcidiacono, Peter. 2004. "Ability Sorting and the Returns to College Major." Journal of Econometrics 121(1-2): 343-375.

[10] Arcidiacono, Peter, Esteban M. Aucejo, Hanming Fang and Ken Spenner. 2011. "Does Affirmative Action Lead to Mismatch? A New Test and Evidence." Quantitative Economics 2(3): 303-333.

[11] Arcidiacono, Peter, Esteban M. Aucejo and Ken Spenner. 2011. "What Happens After Enrollment? An Analysis of the Time Path of Racial Differences in GPA and Major Choice." IZA Journal of Labor Economics $1(5)$.

[12] Arcidiacono, Peter, Esteban M. Aucejo, Patrick Coate and V. Joseph Hotz. 2014. "Affirmative Action and University Fit: Evidence from Proposition 209" IZA Journal of Labor Economics 3(7).

[13] Arcidiacono, Peter, Esteban M. Aucejo and V. Joseph Hotz. 2013. "University Differences in the Graduation of Minorities in STEM Fields: Evidence from California." NBER Working Paper No. 18799.

[14] Arcidiacono, Peter and Cory Koedel. 2014. "Race and College Success: Evidence from Missouri." American Economic Journal: Applied Economics 6(3): 20-57.

[15] Arcidiacono, Peter and Michael F. Lovenheim. Forthcoming. "Affirmative Action and the Quality-Fit Tradeoff." Journal of Economic Literature.

[16] Autor, David H. "Skills, Education, and the Rise of Earnings Inequality Among the 'Other 99 Percent'." Science 344(6186): 843-851.

[17] Autor, David H., Lawrence F. Katz and Melissa S. Kearney. 2008. "Trends in U.S. Wage Inequality: Revising the Revisionists." Review of Economics and Statistics 90(2): 300-323.

[18] Bailey, Martha J. and Susan M. Dynarski. 2011. "Inequality in Postsecondary Education." In G.J. Duncan and R.J. Murnane (eds.), Whither Opportunity? Rising Inequality, Schools, and Children's Life Chances. Russell Sage: New York, New York.

[19] Bettinger, Eric. "How Financial Aid Affects Persistence." In C.M. Hoxby (ed.), College Choices: The Economics of Where to Go, When to Go, and How to Pay for it. University of Chicago Press: Chicago. 
[20] Bettinger, Eric P, Bridgett Terry Long, Philip Oreopoulos, and Lisa Sonbonmatsu. 2012. "The Role of Application Assistance and Information in College Decisions: Results from the H\&R Block Fafsa Experiment." Quarterly Journal of Economics 127(3): 1205-1242.

[21] Bhagat, Geeta Srinivasan. 2004. "The Relationship between factors that Influence College Choice and Persistence in Longhorn Opportunity Scholarship Recipients at The University of Texas at Austin." Doctoral Dissertation at the University of Texas at Austin.

[22] Black, Dan A. and Jeffrey A. Smith. 2004. "How Robust is the Evidence on the Effects of College Quality? Evidence from Matching." Journal of Econometrics 121(1-2): 99-124.

[23] Black, Dan A. and Jeffrey A. Smith. 2006. "Estimating the Returns to College Quality with Multiple Proxies for Quality." Journal of Labor Economics 24(3): 701-728.

[24] Black, Dan A., Kermit Daniel and Jeffrey A. Smith. 2005. "College Quality and Wages in the United States." German Economic Review 6(3): 415-443.

[25] Bound, John, Michael F. Lovenheim and Sarah E. Turner. 2010. "Why Have College Completion Rates Declined? An Analysis of Changing Student Preparation and Collegiate Resources." American Economic Journal: Applied Economics 2(3): 129-157.

[26] Bound, John, Michael F. Lovenheim and Sarah E. Turner. 2012. "Increasing Time to Baccalaureate Degree in the United States." Education Finance and Policy 7(4): 375-424.

[27] Brewer, Dominic J., Eric R. Eide and Ronald G. Ehrenberg. 1999. "Does It Pay to Attend an Elite Private College? Cross-Cohort Evidence on the Effects of College Type on Earnings." Journal of Human Resources 34(1): 104-123.

[28] Cameron, Stephen V. and Christopher Taber. 2004. "Estimation of Educational Borrowing Constraints Using Returns to Schooling." Journal of Political Economy 112(1): 132-182.

[29] Carneiro, Pedro and James J. Heckman. 2002. "The Evidence on Credit Constraints in Post-Secondary Schooling." The Economic Journal 112(482): 705-734.

[30] Clotfelter, Charles T., Steven W. Hemelt, and Helen F. Ladd. 2016. "Multifaceted Aid for Low-Income Students and College Outcomes: Evidence from North Carolina." NBER Working Paper No. 22217.

[31] Cohodes, Sarah and Joshua S. Goodman. 2014. "Merit Aid, College Quality, and College Completion: Massachusetts' Adams Scholarship as an In-Kind Subsidy." American Economic Journal: Applied Economics 6(4): 251-283.

[32] Cornwell, Christopher, David B. Mustard, and Deepa J. Sridhar. 2006. "The Enrollment Effects of MeritBased Financial Aid: Evidence from Georgia's HOPE Program." Journal of Labor Economics 24(4): 761-786.

[33] Cortes, Kalena E. "Do Bans on Affirmative Action Hurt Minority Students? Evidence from the Texas Top 10\% Plan." Economics of Education Review 29(6): 1110-1124.

[34] Cunha, Flavio and James J. Heckman. 2008. "Formulating, Identifying and Estimating the Technology of Cognitive and Noncognitive Skill Formation." Journal of Human Resources 43(4): 738-782.

[35] Cunha, Flavio, James J. Heckman and Susanne M. Schennach. 2010. "Estimating the Technology of Cognitive and Noncognitive Skill Formation." Econometrica 78(3): 883-931.

[36] Dale, Stacey Berg and Alan B. Krueger, 2014. "Estimating the Return to College Selectivity over the Career Using Administrative Earnings Data." Journal of Human Resources 49(2): 323-358.

[37] Dale, Stacey Berg and Alan B. Krueger, 2002. "Estimating the Payoff to Attending A More Selective College: An Application of Selection on Observables and Unobservables." Quarterly Journal of Economics 117(4): 1491-1527.

[38] Daugherty, Lindsay, Francisco Martorell and Isaac McFarlin, Jr. 2014. "Percent Plans, Automatic Admissions, and College Enrollment Outcomes." IZA Journal of Labor Economics 3(10). 
[39] Deming, David J, Justine S Hastings, Thomas J. Kane, and Douglas O. Staiger. 2014. "School Choice, School Quality, and Postsecondary Attainment" American Economic Review 104(3): 991-1013.

[40] Dillon, Eleanor Wiske and Jeffrey Andrew Smith. 2013. "The Determinants of Mismatch Between Students and Colleges." NBER Working Paper No. 19286.

[41] Domina, Thurston. 2007. "Higher Education Policy as Secondary School Reform: Texas Public High Schools after Hopwood." Education Evaluation and Policy Analysis 29(3): 200-217.

[42] Domina, Thurston. 2009. "What Works in College Outreach: Assessing Targeted and Schoolwide Interventions for Disadvantaged Students." Education Evaluation and Policy Analysis 31(2): 127-152.

[43] Dynarski, Susan. 2000. "Hope for Whom? Financial Aid for the Middle Class and Its Impact on College Attendance." National Tax Journal 53(3): 629-661.

[44] Dynarski, Susan and Judith Scott-Clayton. 2013. "Financial Aid Policy: Lessons from Research." Future of Children May.

[45] Dynarski, Susan and Judith Scott-Clayton. 2008. "Complexity and Targeting in Federal Student Aid: A Quantitative Analysis." Tax Policy and the Economy 22: 109-150.

[46] Dynarski, Susan and Judith Scott-Clayton. 2006. "The Cost of Complexity in Student Financial Aid: Lessons from Optimal Tax Theory and Behavioral Economics." National Tax Journal 59(2): 319-356.

[47] Fitzpatrick, Maria D. and Damon Jones. 2012. "Higher Education, Merit-Based Scholarships and PostBaccalaureate Migration." NBER Working Paper No. 18530.

[48] Goldin, Claudia and Lawrence F. Katz. 2007. "Long-Run Changes in the Wage Structure: Narrowing, Widening, Polarizing." Brookings Papers on Economic Activity 2007(2): 135-165.

[49] Haider, Steven and Gary Solon. 2006. "Life-Cycle Variation in the Association between Current and Lifetime Earnings" American Economic Review 96(4): 1308-1320.

[50] Hoekstra, Mark. 2009. "The Effect of Attending the Flagship State University on Earnings: A DiscontinuityBased Approach." Review of Economics and Statistics 91(4): 717-724.

[51] Hoxby, Caroline and Christopher Avery. 2013. "The Missing "One-Offs": The Hidden Supply of HighAchieving, Low-Income Students." Brookings Papers on Economic Activity. Spring: 1-50.

[52] Hoxby, Caroline and Sarah Turner. 2013. "Expanding College Opportunities for High-achieving, Low Income Students." Stanford Institute for Economic Policy Research Discussion Paper 12-014.

[53] Johnson, Matthew T. 2013. "Borrowing Constraints, College Enrollment, and Delayed Entry." Journal of Labor Economics 31(4): 669-725.

[54] Kaine, John F., Daniel M. O'Brien and Paul A. Jargowsky. 2005. "Hopwood and the Top 10 Percent Law: How They Have Affected the College Enrollment Decisions of Texas High School Graduates." Report to the Andrew W. Mellon Foundation: http://www.utdallas.edu/research/tsp-erc/pdf/wp kain 2005 hopwood top 10 percent.pdf.

[55] Kling, Jeffrey R., Jeffrey B. Liebman, and Lawrence F. Katz. 2007. "Experimental Analysis of Neighborhood Effects." Econometrica 75(1): 83119.

[56] Kling, Jeffrey R., Jens Ludwig, and Lawrence F. Katz. 2005. "Neighborhood Effects on Crime for Female and Male Youth: Evidence from a Randomized Housing Voucher Experiment." Quarterly Journal of Economics 120(1): 87130 .

[57] Long, Mark. 2008. "College Quality and Early Adult Outcomes" Economics of Education Review 27(5): 588-602.

[58] Long, Mark and Marta Tienda. 2008. "Winners and Losers: Changes in Texas University Admissions Post-Hopwood." Education Evaluation and Policy Analysis 30(3): 255-280.

[59] Lovenheim, Michael F. and C. Lockwood Reynolds. 2013. "The Effect of Housing Wealth on College Choice: Evidence from the Housing Boom." Journal of Human Resources 48(1): 1-35. 
[60] Ludwig, Jens, Greg J. Duncan, Lisa A. Gennetian, Lawrence F. Katz, Ronald C. Kessler, Jeffrey R. Kling, and Lisa Sanbonmatsu. 2013. "Long-Term Neighborhood Effects on Low-Income Families: Evidence from Moving to Opportunity." American Economic Review 103(3): 22631.

[61] Myers, David, Rob Olsen, Neil Seftor, Julie Young, and Christina Tuttle. 2004. The Impacts of Regular Upward Bound: Results from the Third Follow-up Data Collection. Washington, DC: Mathematica Policy Research.

[62] Niu, Sunny Xinchun and Marta Tienda. 2010. "The Impact of the Texas Top Ten Percent Law on College Enrollment: A Regression Discontinuity Approach." Journal of Policy Analysis and Management 29(1): $84-110$.

[63] Pallais, Amanda. 2015. "Small Differences that Matter: Mistakes in Applying to College." Journal of Labor Economics 33(2): 493-520.

[64] Sacerdote, Bruce. 2001. "Peer Effects With Random Assignment: Results For Dartmouth Roommates." Quarterly Journal of Economics 116(2): 681-704.

[65] Sjoquist, David L. and John V. Winters. 2012. "State Merit-based Financial Aid Programs and College Attainment." IZA Discussion Paper No. 6801.

[66] Stinebrickner, Ralph and Todd R. Stinebrickner. 2006. "What Can be Learned about Peer Effects Using College Roommates? Evidence from New Survey Data and Students from Disadvantaged Backgrounds." Journal of Public Economics 90(8-9): 1435-1454.

[67] Stinebrickner, Ralph and Stinebrickner, Todd. 2008. "The Effect of Credit Constraints on the College Drop-Out Decision: A Direct Approach Using a New Panel Study." American Economic Review 98(5): 2163-2184.

[68] Zimmerman, David J. 2003. "Peer Effects in Academic Outcomes: Evidence from a Natural Experiment." Review of Economics and Statistics 85(1): 9-23. 
Figure 1: UT Austin Longhorn Opportunity Scholars and Comparison Schools

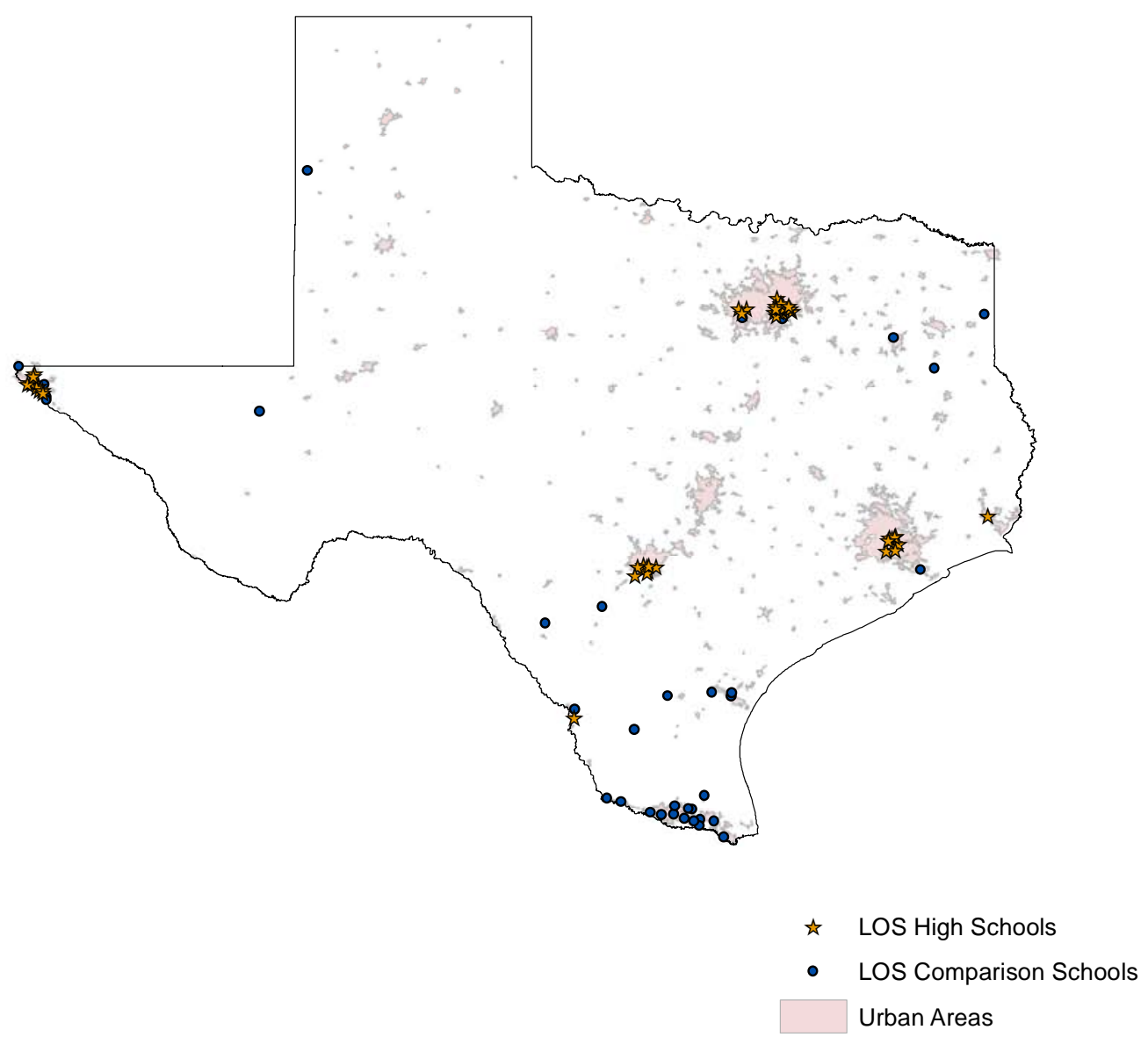


Figure 2: Texas A\&M Century Scholars and Comparison Schools

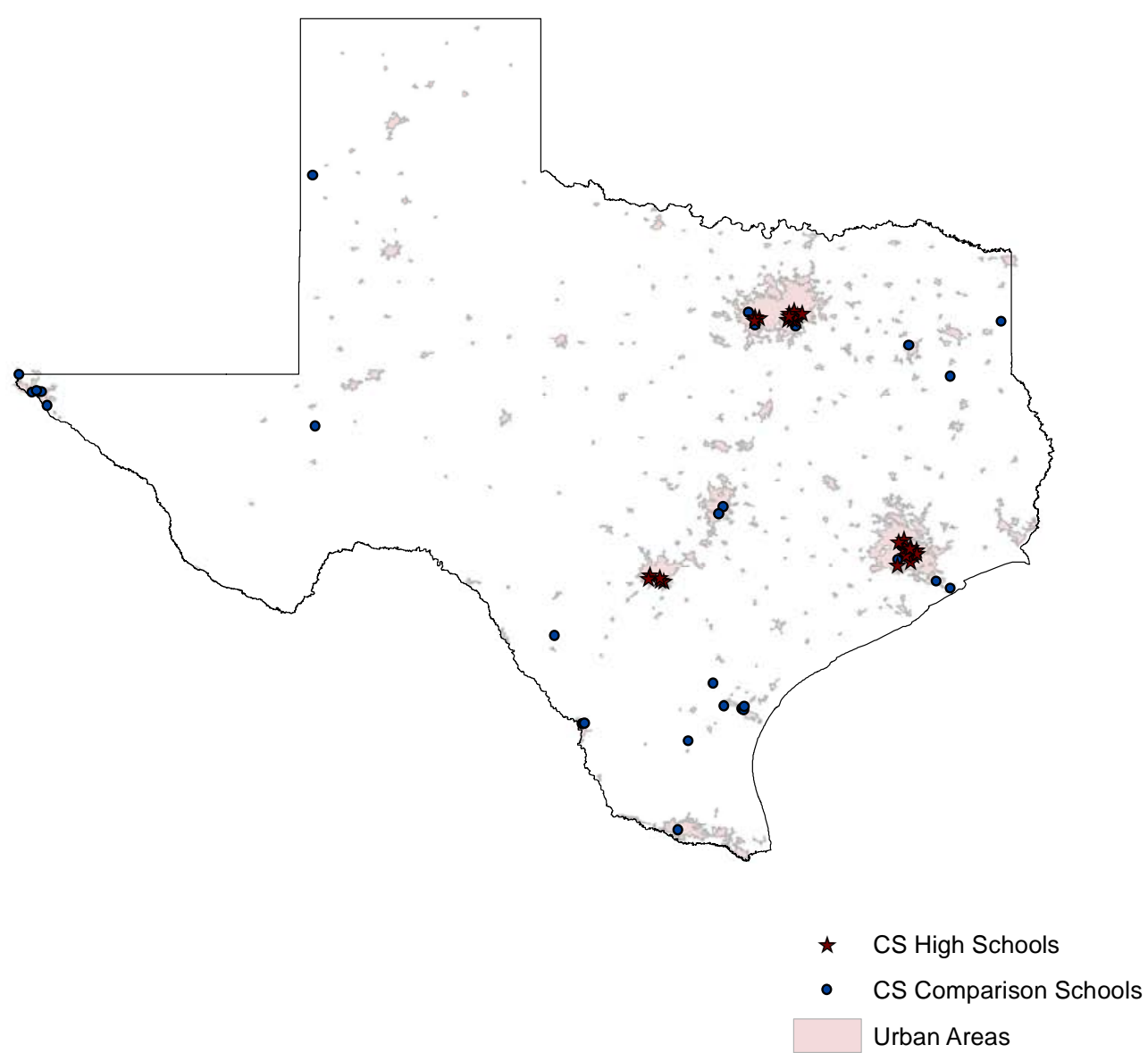


Figure 3: Flagship Enrollment as a Share of All College Attendees by Within High School Achievement Decile
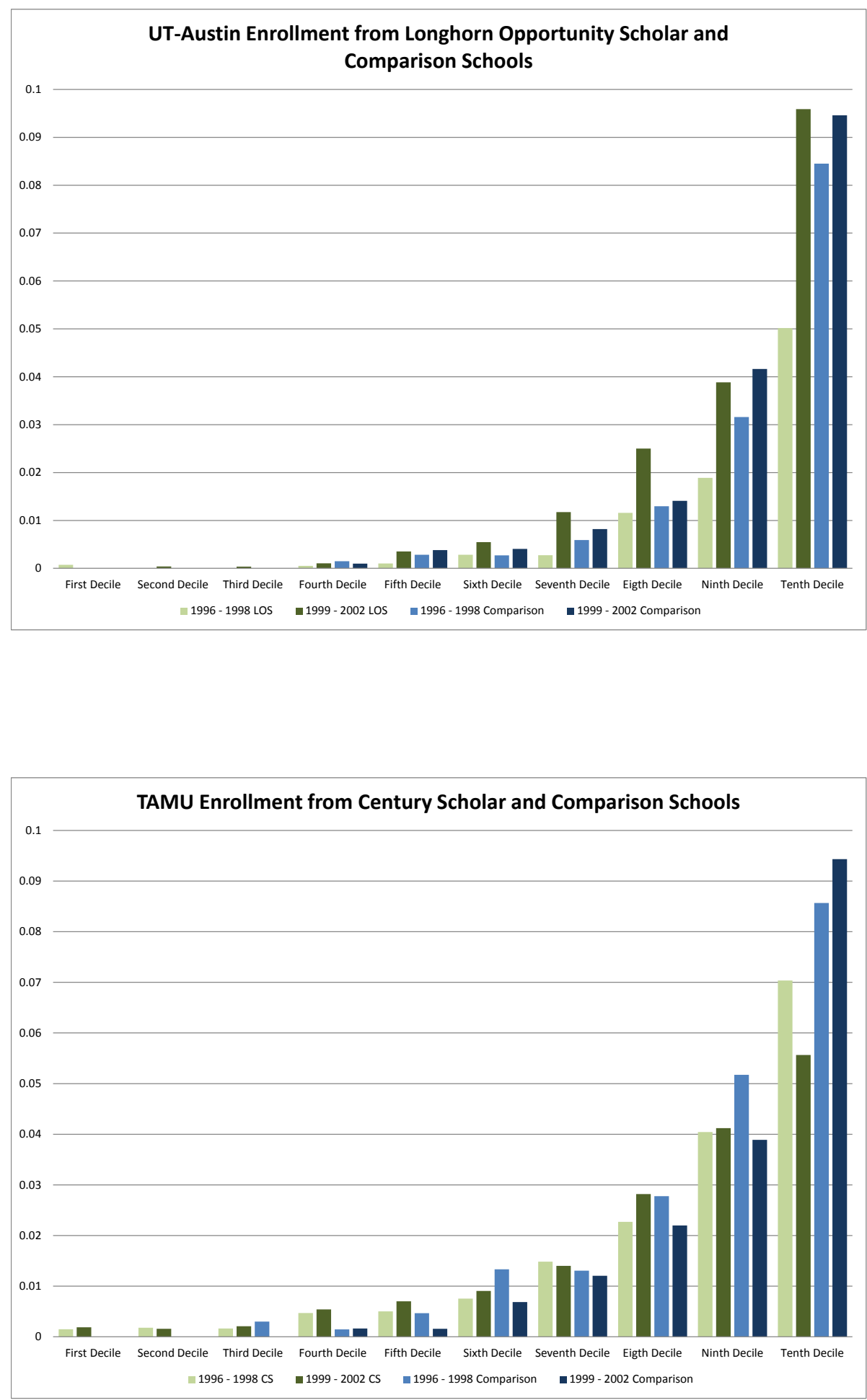
Figure 4: Distribution of LOS and CS Treatment Probabilities by Treatment Status
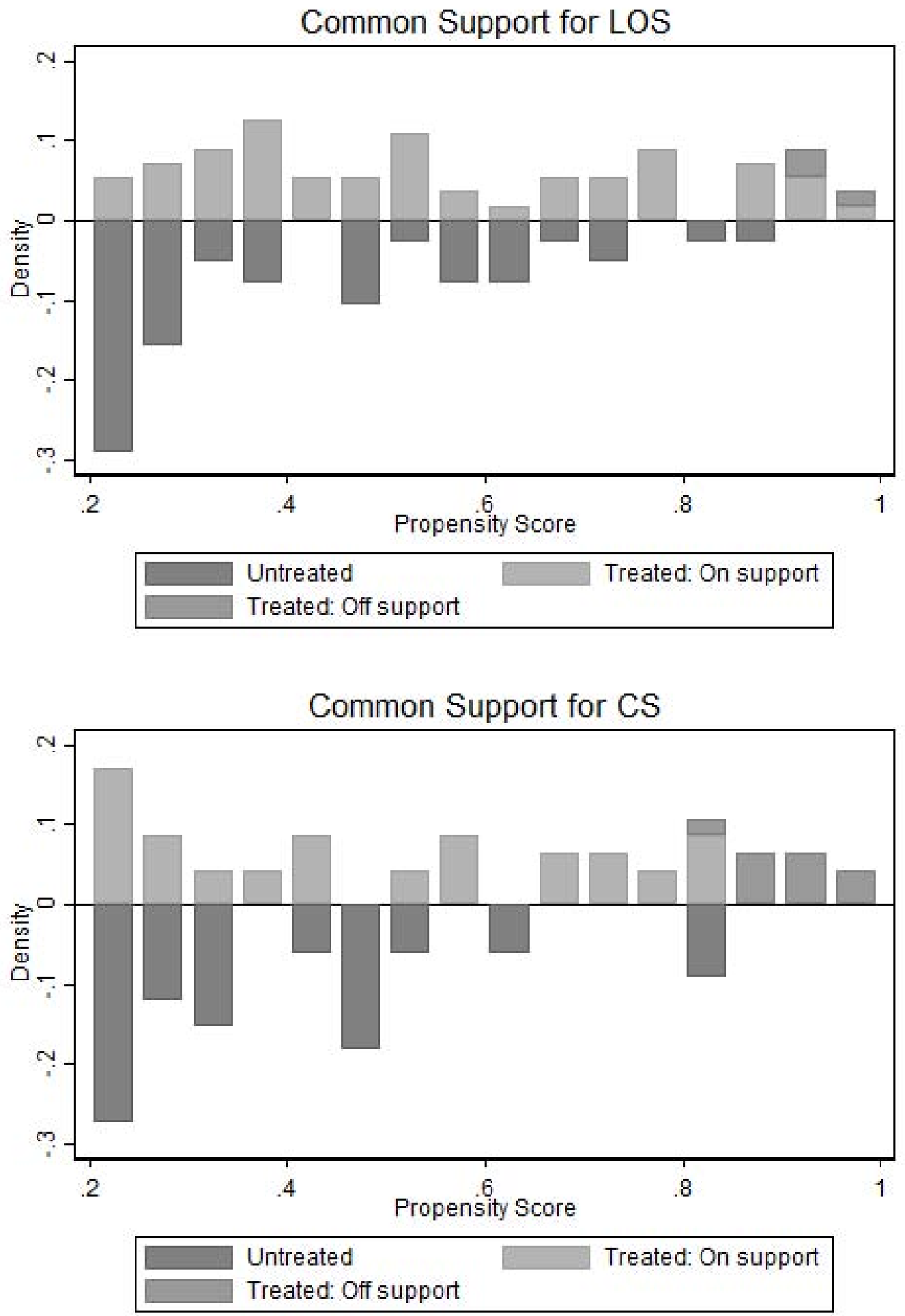

All schools with estimated propensity scores below 0.2 are dropped from the estimation sample. 
Figure 5: Flagship Enrollment Impacts by Year - Top 30\% College Attendees Sample
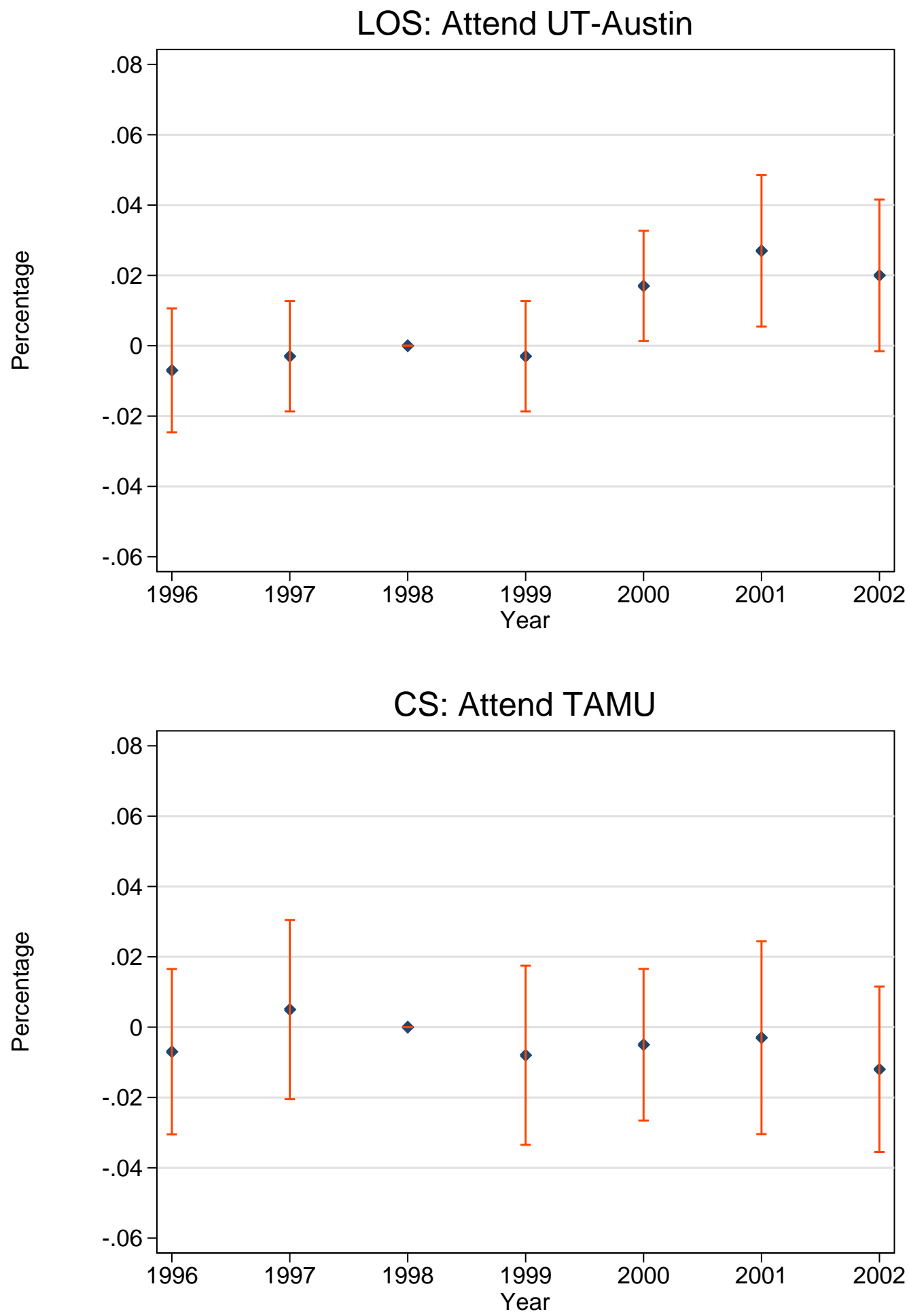

Notes: Authors' estimation as described in the text. Each point represents a coefficient estimate and the bars extending from each point is the $95 \%$ confidence interval calculated from standard errors that are clustered at the high school level. The coefficient in 1998 is set to zero. All models include cohort and high school fixed effects as well as controls for the observed characteristics included in equations (1) and (2). Models also include interactions between a school being eligible for both LOS and CS interacted with each year. 

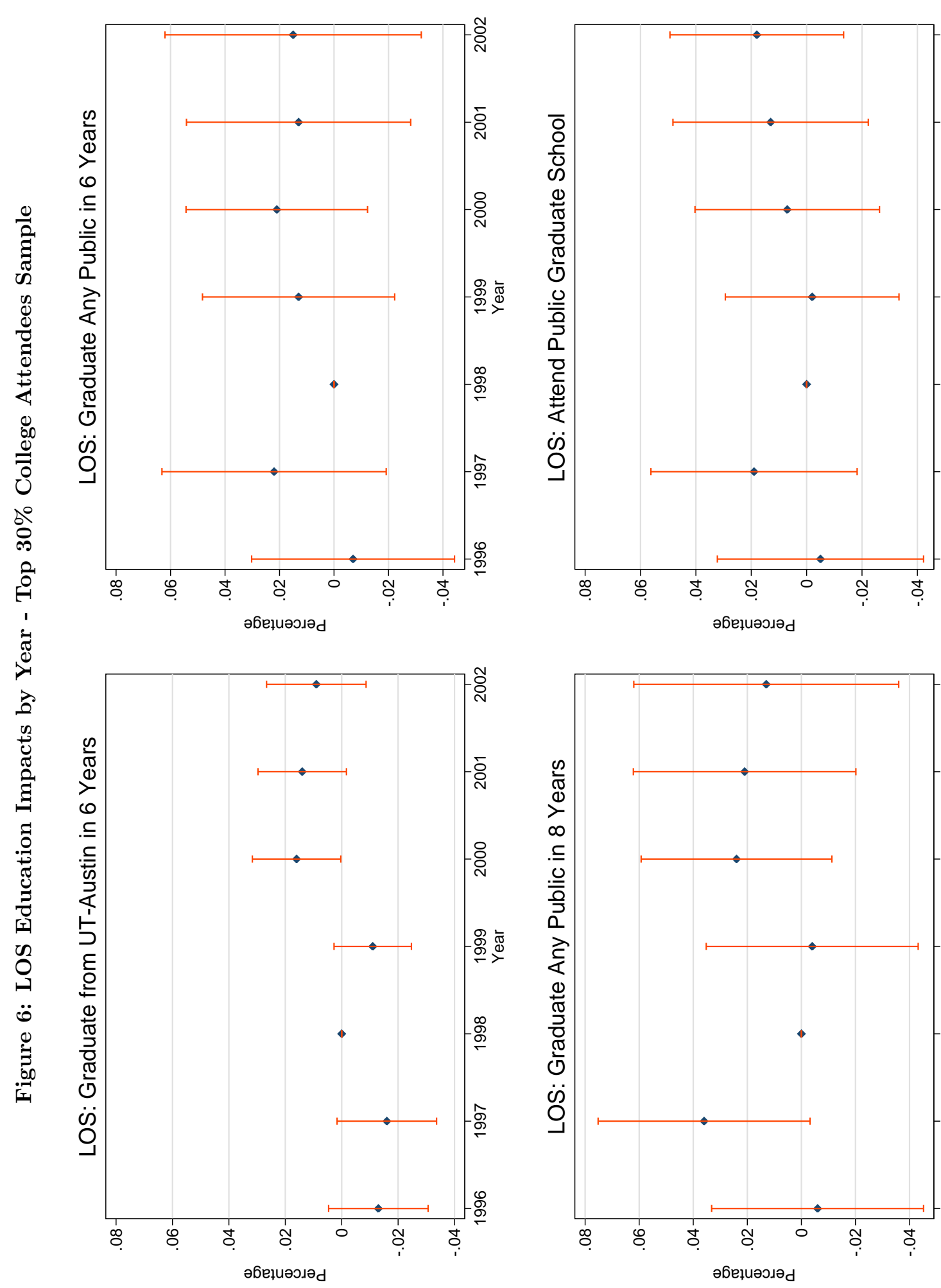

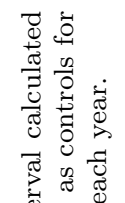

ลั

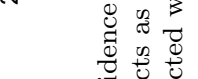

京

so

을

no

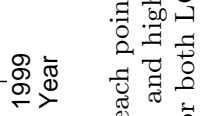

过

$\stackrel{\circ}{\circ} \quad \exists \frac{0}{\circ}$

둘.

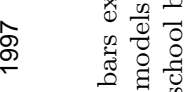

$\pm \approx$

○

(⿻)

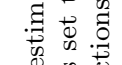

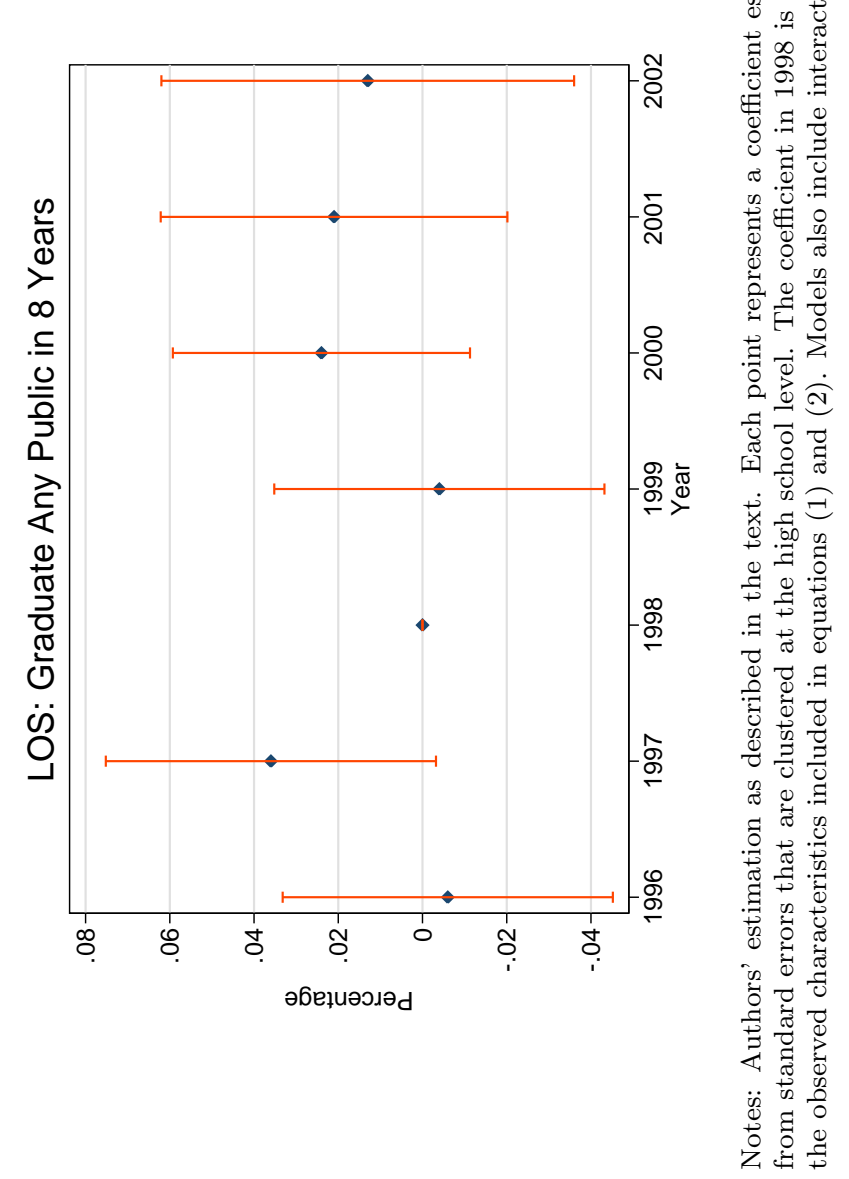




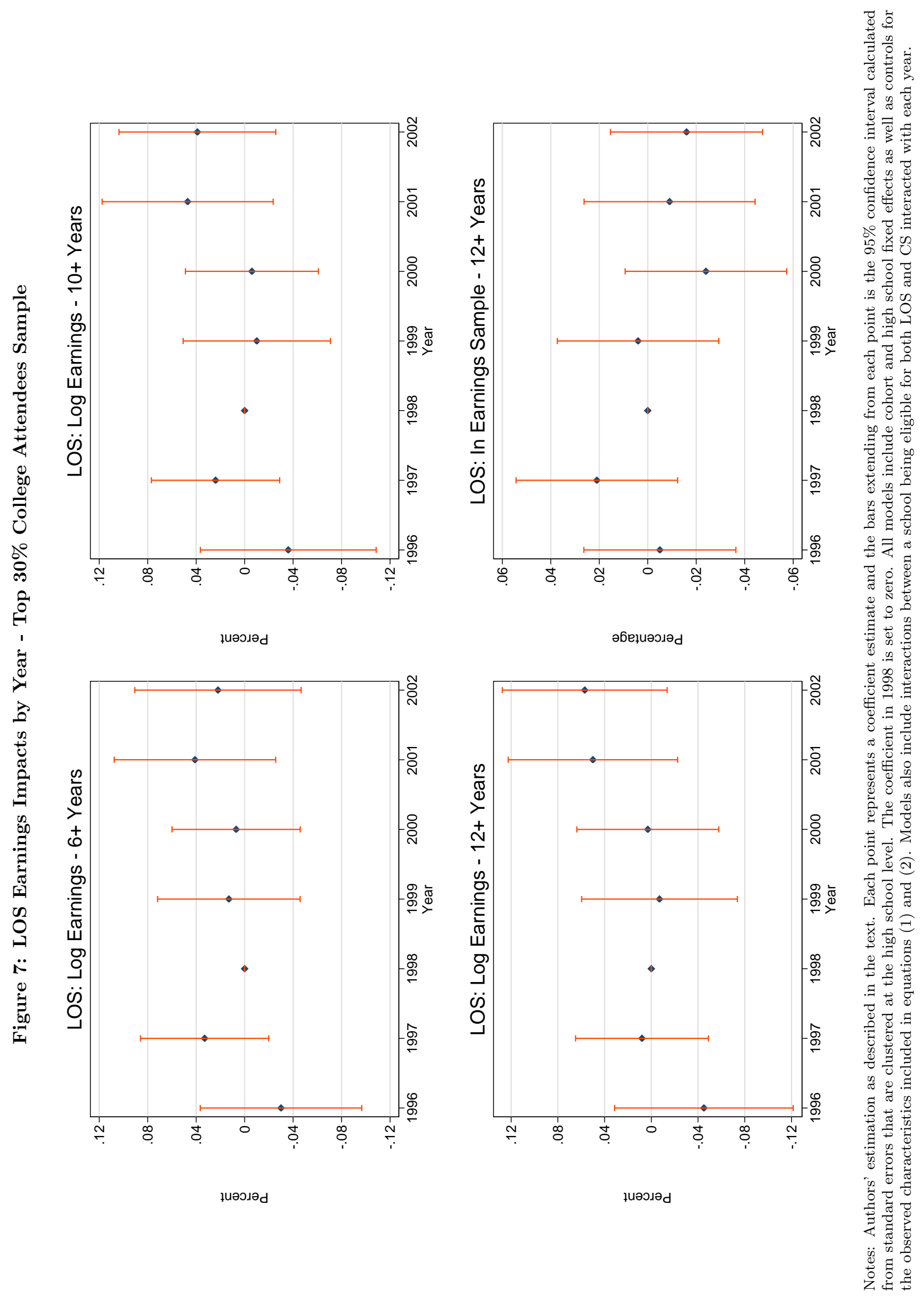


Table 1: Characteristics of Public 4-Year Institutions in Texas

\begin{tabular}{|c|c|c|c|c|}
\hline School Characteristic & UT-Austin & Texas A\&M & $\begin{array}{l}\text { Emerging } \\
\text { Research }\end{array}$ & $\begin{array}{l}\text { Other } \\
\text { 4-Year }\end{array}$ \\
\hline Max USNews Ranking & 53 & 68 & 145 & NA \\
\hline Graduation Rate & 0.79 & 0.79 & 0.47 & 0.37 \\
\hline Retention Rate & 0.94 & 0.91 & 0.76 & 0.64 \\
\hline Avg Full Prof Salary & $\$ 137,871$ & $\$ 128,367$ & $\$ 122,131$ & $\$ 87,352$ \\
\hline UG Student/Faculty FTE & 14.0 & 17.0 & 22.6 & 21.2 \\
\hline Instr Exp per UG Student & $\$ 19,320$ & $\$ 13,421$ & $\$ 7,880$ & $\$ 6,491$ \\
\hline Acad Support Exp per UG Student & $\$ 5,633$ & $\$ 3,853$ & $\$ 2,865$ & $\$ 2,229$ \\
\hline Student Service Exp per UG Student & $\$ 1,761$ & $\$ 1,914$ & $\$ 1,572$ & $\$ 1,387$ \\
\hline SAT Math $75^{\text {th }}$ Percentile & 710 & 630 & 588 & 519 \\
\hline SAT Reading $75^{\text {th }}$ Percentile & 680 & 610 & 553 & 537 \\
\hline Institutions & 1 & 1 & 7 & 21 \\
\hline
\end{tabular}

Means from Integrated Postsecondary Education Data System (IPEDS) provided by the US Department of Education. Data is from 2013-14 except expenditure data, which is from the 2012-13 school year. "Emerging research" universities are institutions declared by the state of Texas to be eligible for special funds to increase research activity. These include UT-Dallas, UT-Arlington, UT-San Antonio, UT-El Paso, Texas Tech and University of Houston. 
Table 2: Summary Statistics for Top 30\% College Attendees Sample - Student Characteristics

\begin{tabular}{lcccc}
\hline & \multicolumn{2}{c}{ LOS Sample } & \multicolumn{2}{c}{ CS Sample } \\
& LOS Schools & LOS Comparison & CS Schools & CS Comparison \\
\hline TAAS Writing & 0.68 & 0.76 & 0.73 & 0.80 \\
(Std Devs) & $(0.38)$ & $(0.36)$ & $(0.38)$ & $(0.35)$ \\
TAAS Reading & 0.62 & 0.69 & 0.67 & 0.74 \\
(Std Devs) & $(0.35)$ & $(0.33)$ & $(0.34)$ & $(0.31)$ \\
TAAS Math & 0.71 & 0.79 & 0.76 & 0.81 \\
(Std Devs) & $(0.41)$ & $(0.37)$ & $(0.40)$ & $(0.36)$ \\
White & 0.08 & 0.12 & 0.12 & 0.27 \\
& $(0.28)$ & $(0.32)$ & $(0.33)$ & $(0.44)$ \\
Black & 0.29 & 0.06 & 0.35 & 0.13 \\
& $(0.45)$ & $(0.25)$ & $(0.48)$ & $(0.34)$ \\
Hispanic & 0.61 & 0.81 & 0.48 & 0.58 \\
& $(0.49)$ & $(0.39)$ & $(0.50)$ & $(0.49)$ \\
Gifted \& Talented & 0.21 & 0.31 & 0.25 & 0.32 \\
& $(0.41)$ & $(0.46)$ & $(0.43)$ & $(0.46)$ \\
At Risk & 0.27 & 0.26 & 0.20 & 0.18 \\
& $(0.45)$ & $(0.44)$ & $(0.40)$ & $(0.38)$ \\
Male & 0.42 & 0.45 & 0.41 & 0.45 \\
& $(0.49)$ & $(0.50)$ & $(0.49)$ & $(0.50)$ \\
Econ. Disadvantaged & 0.49 & 0.57 & 0.41 & 0.31 \\
& $(0.50)$ & $(0.50)$ & $(0.49)$ & $(0.46)$ \\
Observations & & & & \\
\hline
\end{tabular}

Notes: Authors' tabulations using college attendees from the linked ERC-THECB data for the 19962002 high school graduating cohorts. Restricted to trimmed common support and top $30 \%$ of HS class as defined by TAAS achievement index. 
Table 3: Summary Statistics for Top 30\% College Attendees Sample - Outcomes

\begin{tabular}{|c|c|c|c|c|}
\hline & \multicolumn{2}{|c|}{ LOS Sample } & \multicolumn{2}{|c|}{ CS Sample } \\
\hline & LOS Schools & LOS Comparison & CS Schools & CS Comparison \\
\hline \multirow[t]{2}{*}{ Enroll in UT } & 0.043 & 0.047 & 0.048 & 0.084 \\
\hline & $(0.202)$ & $(0.211)$ & $(0.216)$ & $(0.277)$ \\
\hline \multirow[t]{2}{*}{ Enroll in TAMU } & 0.023 & 0.038 & 0.043 & 0.053 \\
\hline & $(0.148)$ & $(0.191)$ & $(0.203)$ & $(0.223)$ \\
\hline Enroll in Emerging & 0.144 & 0.074 & 0.214 & 0.111 \\
\hline Research U & $(0.351)$ & $(0.262)$ & $(0.410)$ & $(0.313)$ \\
\hline Enroll in Other & 0.268 & 0.397 & 0.181 & 0.316 \\
\hline $4-\mathrm{Yr}$ & $(0.443)$ & $(0.489)$ & $(0.385)$ & $(0.465)$ \\
\hline \multirow[t]{2}{*}{ Enroll in $2-Y r$} & 0.522 & 0.443 & 0.513 & 0.438 \\
\hline & $(0.500)$ & $(0.497)$ & $(0.500)$ & $(0.496)$ \\
\hline \multirow[t]{2}{*}{ Transfer } & 0.38 & 0.38 & 0.40 & 0.36 \\
\hline & $(0.48)$ & $(0.48)$ & $(0.49)$ & $(0.48)$ \\
\hline Major in & 0.21 & 0.16 & 0.21 & 0.18 \\
\hline Arts \& Humanities & $(0.41)$ & $(0.37)$ & $(0.41)$ & $(0.38)$ \\
\hline Major in & 0.18 & 0.16 & 0.19 & 0.17 \\
\hline Business & $(0.38)$ & $(0.37)$ & $(0.39)$ & $(0.38)$ \\
\hline Major in & 0.08 & 0.09 & 0.08 & 0.10 \\
\hline Social Science & $(0.27)$ & $(0.29)$ & $(0.27)$ & $(0.30)$ \\
\hline Major in & 0.10 & 0.14 & 0.11 & 0.14 \\
\hline STEM & $(0.30)$ & $(0.34)$ & $(0.31)$ & $(0.35)$ \\
\hline Graduate UT & 0.031 & 0.036 & 0.039 & 0.075 \\
\hline in 6 Yrs & $(0.174)$ & $(0.185)$ & $(0.193)$ & $(0.263)$ \\
\hline Graduate TAMU & 0.015 & 0.032 & 0.032 & 0.047 \\
\hline in 6 Yrs & $(0.122)$ & $(0.176)$ & $(0.177)$ & $(0.212)$ \\
\hline Any Public BA & 0.209 & 0.316 & 0.243 & 0.343 \\
\hline in 6 Yrs. & $(0.406)$ & $(0.465)$ & $(0.429)$ & $(0.475)$ \\
\hline Has 5 qtrs of Earnings & 0.78 & 0.78 & 0.81 & 0.75 \\
\hline (12+ Yrs after HS) & $(0.41)$ & $(0.42)$ & $(0.39)$ & $(0.44)$ \\
\hline Observations & 17,797 & 12,475 & 12,265 & 9,062 \\
\hline Resid. Log Earn & -0.046 & 0.022 & 0.035 & 0.072 \\
\hline (12) & (0.170) & (0.100) & (0.170) & (0.17) \\
\hline Observations & 13,944 & 9,683 & 9,963 & 6,755 \\
\hline
\end{tabular}

Notes: Authors' tabulations using college attendees from the linked ERC-THECB data for the 1996-2002 high school graduating cohorts. Restricted to trimmed common support and top $30 \%$ of HS class as defined by TAAS achievement index. 


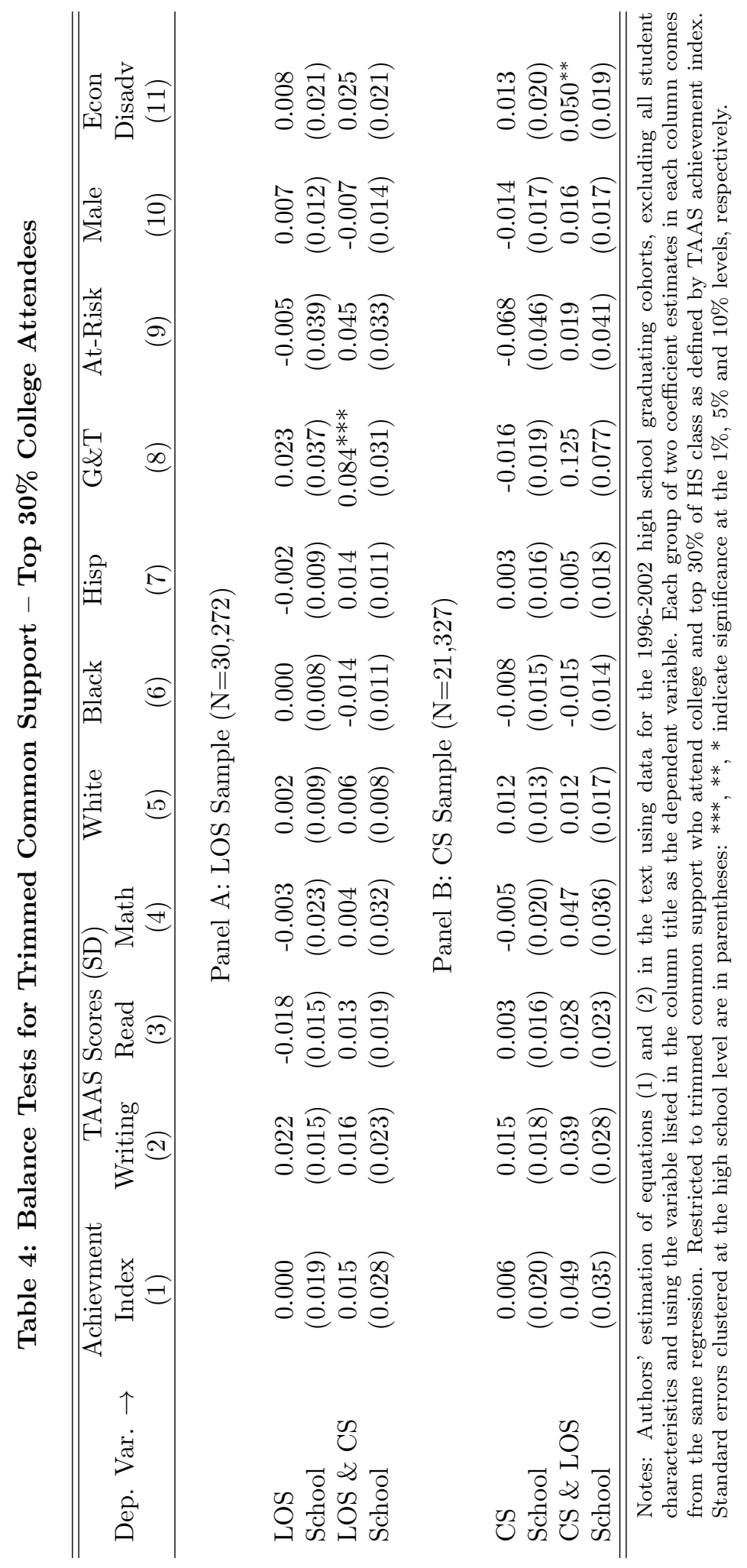


Table 5: The Effect of the Longhorn Opportunity and Century Scholars Programs on College Enrollment

\begin{tabular}{|c|c|c|c|c|c|c|}
\hline Treatment & $\begin{array}{c}\text { Attend Any } \\
\text { TX College } \\
\text { (1) }\end{array}$ & $\begin{array}{l}\text { Attend } \\
\text { UT } \\
(2)\end{array}$ & $\begin{array}{l}\text { Attend } \\
\text { TAMU } \\
(3)\end{array}$ & $\begin{array}{c}\text { Attend Other } \\
\text { Research U } \\
(4)\end{array}$ & $\begin{array}{c}\text { Attend Other } \\
4 \mathrm{Yr} \\
(5)\end{array}$ & $\begin{array}{c}\text { Attend } \\
2 \mathrm{yr} \\
(6)\end{array}$ \\
\hline \multicolumn{7}{|c|}{ Panel A: Longhorn Opportunity Scholar Program } \\
\hline & HS Grads & \multicolumn{5}{|c|}{ College Attendees } \\
\hline LOS School & $\begin{array}{c}0.003 \\
(0.012)\end{array}$ & $\begin{array}{c}0.022 * * * * \\
(0.005)\end{array}$ & $\begin{array}{l}-0.009 \\
(0.006)\end{array}$ & $\begin{array}{c}-0.025^{* *} \\
(0.010)\end{array}$ & $\begin{array}{l}-0.005 \\
(0.013)\end{array}$ & $\begin{array}{c}0.016 \\
(0.015)\end{array}$ \\
\hline LOS \& CS & -0.015 & -0.010 & $0.012^{* *}$ & 0.009 & -0.010 & -0.001 \\
\hline School & $(0.012)$ & $(0.008)$ & $(0.006)$ & $(0.011)$ & $(0.015)$ & $(0.018)$ \\
\hline \multicolumn{7}{|c|}{$\begin{array}{l}\text { Panel B: Century Scholars Program } \\
\text { College Attendees }\end{array}$} \\
\hline CS School & $\begin{array}{c}-0.022 \\
(0.014)\end{array}$ & $\begin{array}{c}0.002 \\
(0.019)\end{array}$ & $\begin{array}{c}0.001 \\
(0.009)\end{array}$ & $\begin{array}{c}-0.027^{* *} \\
(0.014)\end{array}$ & $\begin{array}{c}0.032^{*} \\
(0.018)\end{array}$ & $\begin{array}{l}-0.008 \\
(0.016)\end{array}$ \\
\hline CS \& LOS & -0.006 & $0.024^{* *}$ & -0.003 & 0.006 & $-0.036^{* *}$ & 0.009 \\
\hline School & $(0.013)$ & $(0.012)$ & $(0.011)$ & $(0.014)$ & $(0.014)$ & $(0.017)$ \\
\hline
\end{tabular}

Notes: Estimation of equations (1) and (2) in the text using the linked ERC-THECB data for the 1996-2002 high school graduating cohorts. Each group of two coefficient estimates in each column comes from the same regression. All models include high school and year fixed effects as well as the demographic, high school and test score controls discussed in Section 4 of the text. Restricted to trimmed common support and top 30\% of HS class as defined by TAAS achievement index. Sample sizes for the LOS college attendee and HS grad samples are 30,272 and 41,588, respectively. For CS the sample sizes are 21,327 and 30,027, respectively. Standard errors clustered at the high school level are in parentheses: $* * *, * *, *$ indicate significance at the $1 \%, 5 \%$ and $10 \%$ levels, respectively. 


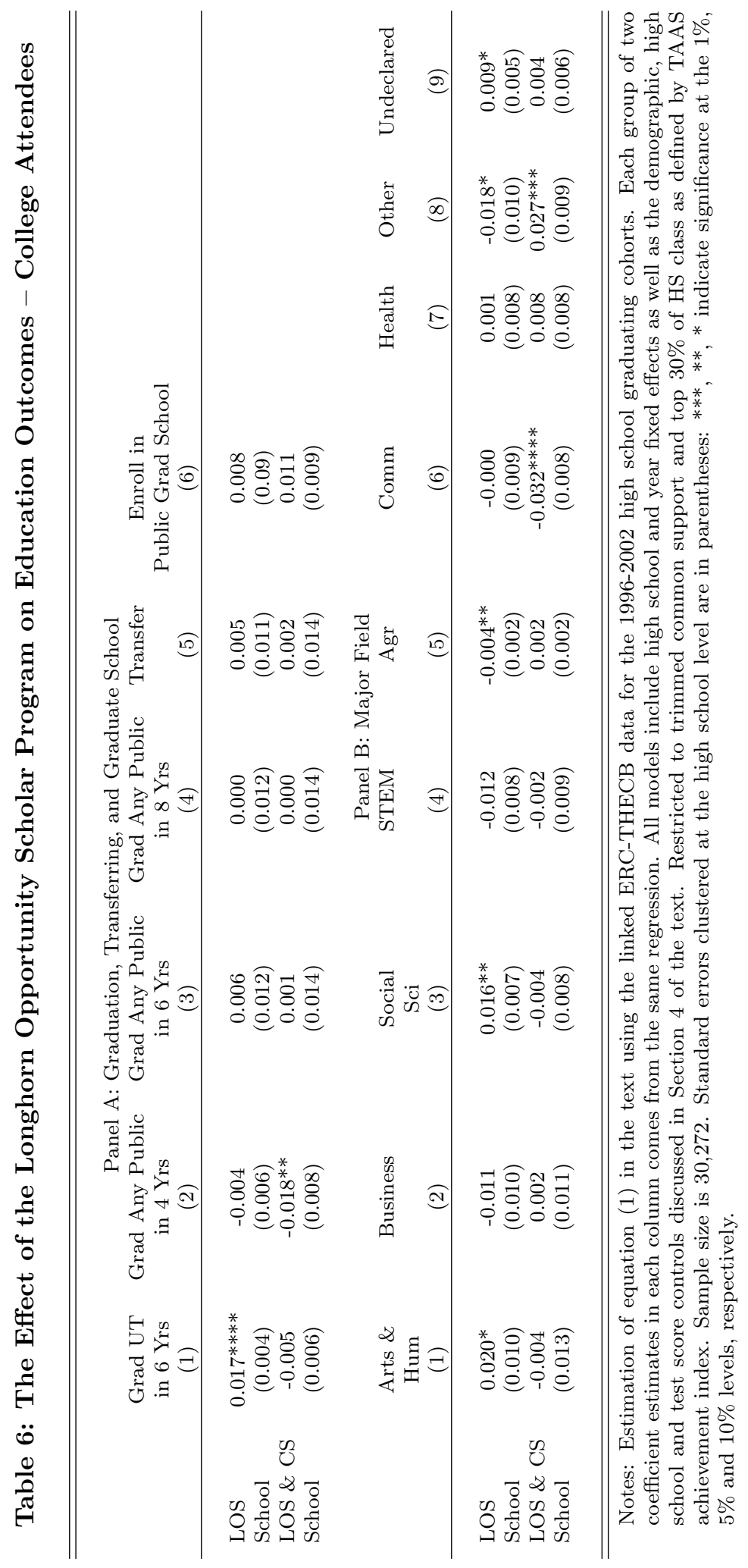


Table 7: Effect of LOS on College Graduation Pathways

\begin{tabular}{|c|c|c|c|}
\hline & $\begin{array}{c}\text { \& Grad Flagship } \\
(1)\end{array}$ & $\begin{array}{c}\text { Start UT } \\
\& \text { Grad Non-Flagship } \\
(2)\end{array}$ & $\begin{array}{c}\text { \& No TX Public BA } \\
(3)\end{array}$ \\
\hline \multirow[t]{2}{*}{ LOS School } & $0.016^{* * * *}$ & 0.001 & $0.005^{*}$ \\
\hline & $(0.004)$ & $(0.002)$ & $(0.002)$ \\
\hline \multirow[t]{2}{*}{ LOS \& CS School } & -0.006 & -0.002 & -0.002 \\
\hline & $\begin{array}{c}\text { \& Grad Flagship } \\
\text { (1) }\end{array}$ & $\begin{array}{c}\text { Start TAMU } \\
\text { \& Grad Non-Flagship } \\
(2)\end{array}$ & \& No TX Public BA \\
\hline \multirow{3}{*}{$\begin{array}{l}\text { LOS School } \\
\text { LOS \& CS School }\end{array}$} & $\begin{array}{l}-0.007 \\
(0.004)\end{array}$ & $\begin{array}{l}-0.000 \\
(0.002)\end{array}$ & $\begin{array}{l}-0.001 \\
(0.002)\end{array}$ \\
\hline & $\begin{array}{c}0.008^{* *} \\
(0.004)\end{array}$ & $\begin{array}{c}0.000 \\
(0.001)\end{array}$ & $\begin{array}{l}0.004^{*} \\
(0.002)\end{array}$ \\
\hline & $\begin{array}{c}\text { \& Grad Flagship } \\
(1)\end{array}$ & $\begin{array}{l}\text { Start Emerging Research } \\
\text { \& Grad Non-Flagship } \\
(2)\end{array}$ & $\begin{array}{l}\text { U } \\
\& \text { No TX Public BA } \\
\qquad(3)\end{array}$ \\
\hline LOS School & $\begin{array}{l}-0.000 \\
(0.001)\end{array}$ & $\begin{array}{c}-0.012^{* *} \\
(0.006)\end{array}$ & $\begin{array}{l}-0.012^{*} \\
(0.007)\end{array}$ \\
\hline \multirow[t]{2}{*}{ LOS \& CS School } & $\begin{array}{l}-0.000 \\
(0.001)\end{array}$ & $\begin{array}{c}0.008 \\
(0.006)\end{array}$ & $\begin{array}{c}0.002 \\
(0.008)\end{array}$ \\
\hline & $\begin{array}{l}\text { \& Grad Flagship } \\
(1)\end{array}$ & $\begin{array}{c}\text { Start Other } 4 \text { Yr } \\
\& \text { Grad Non-Flagship } \\
(2)\end{array}$ & $\begin{array}{c}\text { \& No TX Public BA } \\
(3)\end{array}$ \\
\hline LOS School & $\begin{array}{c}0.002 \\
(0.001)\end{array}$ & $\begin{array}{c}-0.002 \\
(0.010)\end{array}$ & $\begin{array}{l}-0.004 \\
(0.009)\end{array}$ \\
\hline \multirow[t]{2}{*}{ LOS \& CS School } & $\begin{array}{c}0.001 \\
(0.001)\end{array}$ & $\begin{array}{l}-0.007 \\
(0.009)\end{array}$ & $\begin{array}{l}-0.005 \\
(0.010)\end{array}$ \\
\hline & $\begin{array}{l}\text { \& Grad Flagship } \\
(1)\end{array}$ & $\begin{array}{c}\text { Start 2 Yr } \\
\text { \& Grad Non-Flagship } \\
(2)\end{array}$ & $\begin{array}{c}\text { \& No TX Public BA } \\
(3)\end{array}$ \\
\hline LOS School & $\begin{array}{c}0.002 \\
(0.002)\end{array}$ & $\begin{array}{c}0.006 \\
(0.007)\end{array}$ & $\begin{array}{c}0.007 \\
(0.014)\end{array}$ \\
\hline LOS \& CS School & $\begin{array}{c}0.001 \\
(0.001)\end{array}$ & $\begin{array}{c}0.002 \\
(0.007)\end{array}$ & $\begin{array}{l}-0.004 \\
(0.017)\end{array}$ \\
\hline
\end{tabular}

Notes: Estimation of equation (1) in the text using the linked ERC-THECB data for the 1996-2002 high school graduating cohorts. Each group of two coefficient estimates in each column comes from the same regression. All models include high school and year fixed effects as well as the demographic, high school and test score controls discussed in Section 4 of the text. Restricted to trimmed common support for college attendees and top $30 \%$ of HS class as defined by TAAS achievement index. Sample size is 30,272 for all regressions. Standard errors clustered at the high school level are in parentheses: $* * *, * *, *$ indicate significance at the $1 \%, 5 \%$ and $10 \%$ levels, respectively. 
Table 8: The Effect of the Longhorn Opportunity Scholar Program on Earnings - College Attendees

\begin{tabular}{lcc|cc|cc}
\hline \hline & $\begin{array}{c}\text { In 6 Year } \\
\text { Earn Sample } \\
(1)\end{array}$ & $\begin{array}{c}\text { Ln(Adj Earn) } \\
\text { 6 Yrs After HS } \\
(2)\end{array}$ & $\begin{array}{c}\text { In 10 Year } \\
\text { Earn Sample } \\
(3)\end{array}$ & $\begin{array}{c}\text { Ln(Adj Earn) } \\
\text { 10 Yrs After HS } \\
(4)\end{array}$ & $\begin{array}{c}\text { In 12 Year } \\
\text { Earn Sample } \\
(5)\end{array}$ & $\begin{array}{c}\text { Ln(Adj Earn) } \\
12 \text { Yrs After HS } \\
(6)\end{array}$ \\
\hline LOS & $-0.015^{* *}$ & 0.014 & -0.015 & 0.020 & $-0.019^{* *}$ & $0.040^{* *}$ \\
School & $(0.007)$ & $(0.016)$ & $(0.009)$ & $(0.017)$ & $(0.009)$ & $(0.018)$ \\
LOS \& CS & $0.012^{*}$ & 0.003 & 0.015 & -0.014 & 0.013 & -0.021 \\
School & $(0.007)$ & $(0.017)$ & $(0.009)$ & $(0.018)$ & $(0.010)$ & $(0.021)$ \\
Observations & 30,272 & 26,512 & 30,272 & 24,106 & 30,272 & 23,627 \\
\hline \hline
\end{tabular}

Notes: Estimation of equation (1) in the text using the linked ERC-THECB data for the 1996-2002 high school graduating cohorts. Each group of two coefficient estimates in each column comes from the same regression. All models include high school and year fixed effects as well as the demographic, high school and test score controls discussed in Section 4 of the text. Restricted to trimmed common support and top $30 \%$ of HS class as defined by TAAS achievement index. Ln(Adj Earn) is calculated as the average residual from a regression of log quarterly earnings on cohort-by-quarter-year indicators. Only earnings among those with 5 quarters of earnings over $\$ 100$ in the relevant time period are included. The highest $0.5 \%$ of earnings quarters are excluded from the analysis sample. Standard errors clustered at the high school level are in parentheses: ***, **, * indicate significance at the $1 \%, 5 \%$ and $10 \%$ levels, respectively. 


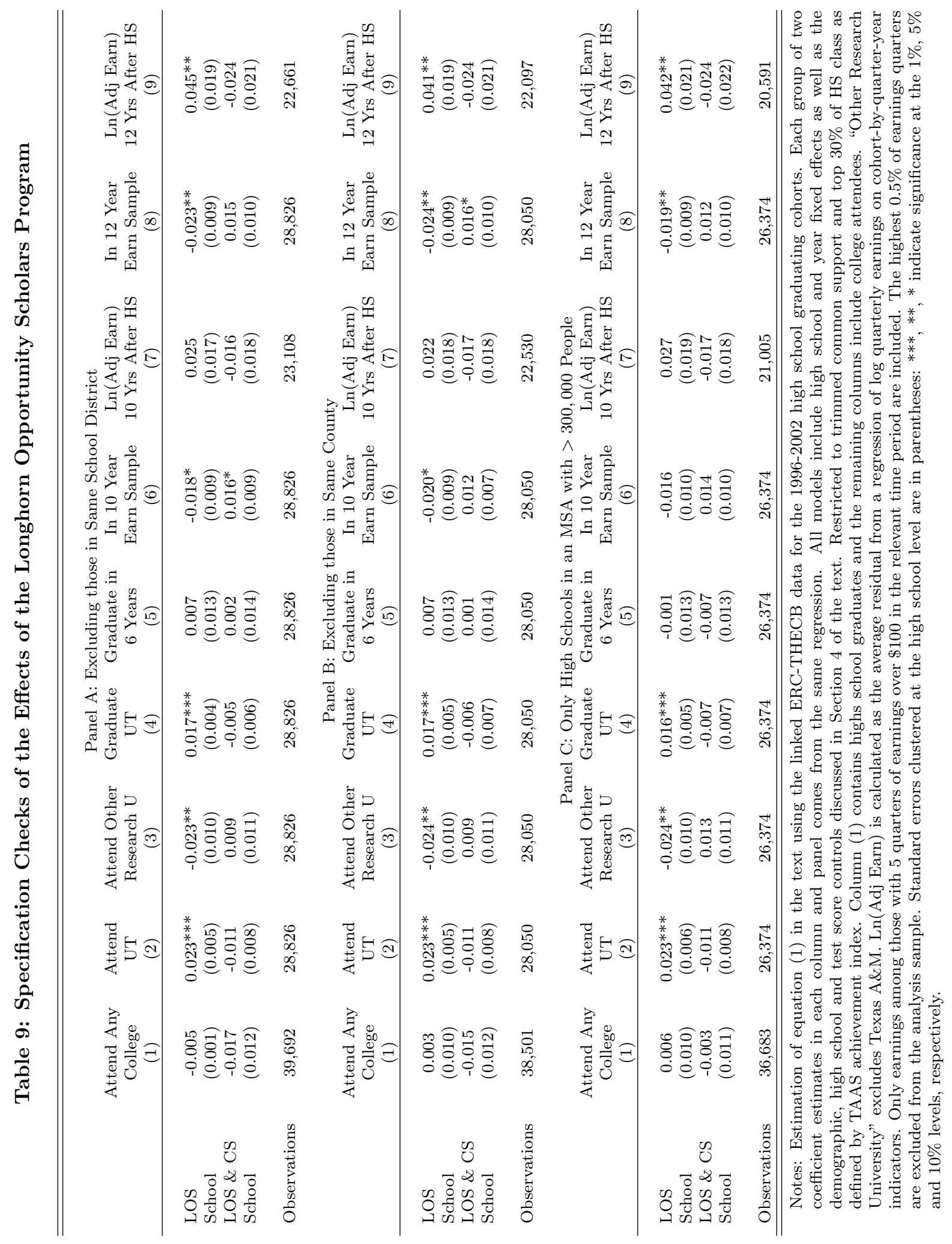




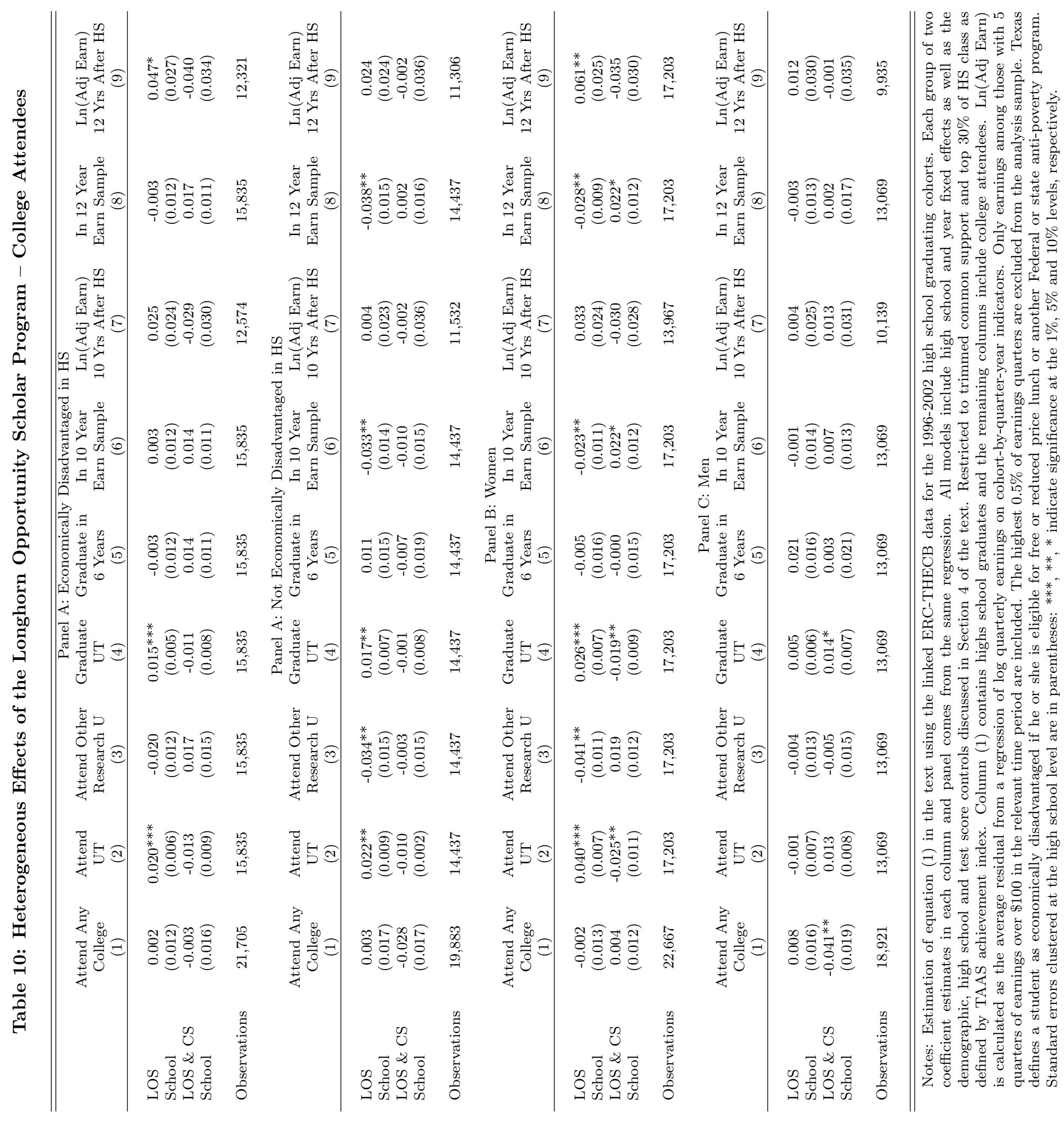

